\title{
Finite element analysis of heat generation in dissimilar alloy ultrasonic welding
}

\author{
Jedrasiak P. ${ }^{1,2}$ and Shercliff H.R. ${ }^{1, *}$ \\ ${ }^{1}$ Department of Engineering, University of Cambridge, Trumpington St, CB2 1PZ, UK. \\ ${ }^{2}$ TWI, Granta Park, Cambridge, CB21 6AL, UK \\ * Corresponding author: hrs@eng.cam.ac.uk (44-1223-332683)
}

\begin{abstract}
This paper presents a computationally efficient finite element analysis of the heat generation in ultrasonic welding (USW). The temperature field is predicted from a continuous thermal model, with the heat generation rate being calculated intermittently, using a deformation model for single cycles of oscillation. The model was applied to USW of Al 6111 to itself, and to DC04 steel and Ti6Al4V, with plastic deformation only occurring in the $\mathrm{Al}$ alloy. Ultrasonic softening was allowed for empirically in the constitutive plastic response of the $\mathrm{Al}$ alloy. The predicted heat generation rate for all three material combinations was consistent with that inferred from thermocouple data and the thermal model. Material deformation maps were developed as a means of illustrating the dominant deformation regime of temperature and strain-rate. The thermal and deformation models were then fully coupled, as a proof of concept, to demonstrate that the power and temperature histories can be predicted directly from the constitutive data for the alloy and a kinematic description of the process.
\end{abstract}

\section{Keywords}

Ultrasonic welding; aluminium alloys; titanium alloys; carbon steels; process modelling; finite element analysis.

Declarations of interest: none

\section{Introduction}

Ultrasonic welding (USW) in metals is a solid-state joining process for making lap welds, in which high-frequency vibrations are applied parallel to the weld interface under a static clamping pressure. As a solid state joining method, USW avoids many of the undesirable phenomena observed in fusion welding of metals, such as solidification cracking, grain boundary liquation cracking, porosity and micro-segregation, while enabling the control of the formation of brittle intermetallic phases in dissimilar metal welding [1-4]. The process has become applicable to sheet metal up to a few mm thick, thanks to the availability of higher power welding systems. These are capable of joining many alloys, including dissimilar combinations provided: (i) at least one of the alloys is sufficiently soft; (ii) detrimental interface reactions can be avoided. Its range of application has therefore extended beyond electronics to automotive alloys, as part of the development of lighter vehicles. In this context, USW can compete with alternative fusion-based processes, such as resistance spot welding (RSW), as it is comparably fast (potentially less than $0.5 \mathrm{~s}$ ).

A number of authors have studied metallic USW experimentally, measuring weld temperatures and the influence of welding parameters, such as tool design and weld time, on the resulting microstructures and joint properties. The welds modelled in this paper were produced in a collaborative research project with Manchester University Materials Science Centre. The key results from this work are summarised first, as they provide the experimental basis for the model. Other relevant experimental work is then discussed below, alongside the review of modelling of USW. 
Bakavos et al. [1] investigated weld formation and microstructure evolution in $\mathrm{Al} \mathrm{6111,} \mathrm{showing} \mathrm{that}$ welding proceeds initially by sliding friction, flattening the asperities until full contact is achieved, leading to bulk plastic deformation. This work was extended by Chen et al. [5] to describe the dissolution of strengthening phases in the deformation and heat-affected zones, and subsequent strength recovery by natural ageing. Prangnell et al. [2] successfully joined Al 6111 and DC04 steel, with all of the deformation occurring in the Al sheet, but with lower joint strength than in Al-Al welds due to the growth of an intermetallic reaction layer. Dissimilar Al-Ti ultrasonic welds however gave comparable strength to Al-Al welds, which was attributed to the lack of formation of brittle intermetallics (Zhang et al. [4,6]). Attempts to ultrasonically weld Al 6111 to Mg AZ31 reported by Panteli et al. [3] and Robson et al. [7] were less successful than Mg-Mg USW, with poor fracture behaviour due to the rapid development of a thick IMC layer at the joint interface, and eutectic melting at the interface for welding times over $1 \mathrm{~s}$.

The application of modelling in this paper aims to interpret these experiments, with a focus on the evolution of the temperature and deformation history in the bond region, enabling the development of microstructure models for precipitate evolution in age hardening $\mathrm{Al}$ alloys, and interface reactions in the dissimilar alloy welds. A thermal model developed previously [8] predicted the temperature cycles with good accuracy, when calibrated to thermocouple data for each alloy combination to establish the history of power input to the workpiece. In common with many USW machines, the equipment used in Manchester gave limited information on the power history, only giving a net energy based on a nominal machine power and weld time. The challenge therefore is to predict the heat generation from first principles, to reduce the dependence on instrumented welds, while also predicting the strain-rate at the interface, which influences interpretation and modelling of the dislocation-accelerated kinetics of intermetallic reactions at the interface [9].

\section{Literature Review: Modelling of USW}

A number of attempts at thermomechanical modelling of ultrasonic metal welding have been published to date, for both spot and seam welding variants. In common with all thermomechanical modelling of solid-state friction-based welding processes, consideration needs to be given to the following issues: (a) the evolution of the interface boundary conditions; (b) the specification of the heat input throughout welding; (c) the choice of a suitable constitutive material model, complicated in the context of USW by the effect of ultrasonic softening; (d) validation of the heat input, and the resulting temperature and deformation histories. Table 1 summarises how these issues have been addressed in the literature, in almost all cases using 2D or 3D finite element analysis. The objectives of these studies, and the ways in which the key issues (a-d) have been addressed, are then discussed below. Consideration is also given to the need for computational efficiency, the limitation in USW being the very high frequency and thus large number of cycles, even for weld times under 1 second. 
Table X: Summary of thermomechanical modelling of USW, and approaches to the core modelling issues

\begin{tabular}{|c|c|c|c|c|c|}
\hline $\begin{array}{l}\text { Authors / } \\
\text { references }\end{array}$ & $\begin{array}{l}\text { Material and } \\
\text { geometry }\end{array}$ & Contact conditions & Heat input & Material constitutive data & $\begin{array}{l}\text { Experimental validation / } \\
\text { calibration }\end{array}$ \\
\hline $\begin{array}{l}\text { Elangovan } \\
\text { et al. }[10,11]\end{array}$ & $\begin{array}{l}\mathrm{Al} \text { sheet; } \mathrm{Al}_{2} \mathrm{O}_{3} \\
\mathrm{Al}-\mathrm{Al} \text { and } \\
\text { dissimilar } \mathrm{Al}- \\
\mathrm{Al}_{2} \mathrm{O}_{3} \text { spot welds }\end{array}$ & $\begin{array}{l}\text { Constant coefficient of } \\
\text { friction }\end{array}$ & $\begin{array}{l}\text { Two uniform, constant heat } \\
\text { fluxes (one for friction, one for } \\
\text { deformation, applied over } \\
\text { different areas). }\end{array}$ & $\begin{array}{l}\text { Constant yield stress, independent } \\
\text { of temperature }\end{array}$ & Temperature \\
\hline $\begin{array}{l}\text { Siddiq and } \\
\text { Ghassemieh } \\
{[12,13]}\end{array}$ & $\begin{array}{l}\text { Al } 6061 \text { foil and } \\
\text { sheet; Al } 3003 \\
\text { foil and sheet; } \\
\text { seam weld }\end{array}$ & $\begin{array}{l}\text { Calibrated coefficient of } \\
\text { friction, dependent on } \\
\text { process conditions }\end{array}$ & $\begin{array}{l}\text { Surface friction and bulk } \\
\text { plasticity }\end{array}$ & $\begin{array}{l}\text { Cyclic plasticity model with } \\
\text { thermal and acoustic (ultrasonic) } \\
\text { softening, and no strain-rate } \\
\text { dependence. }\end{array}$ & $\begin{array}{l}\text { No direct validation, only } \\
\text { empirical correlations between } \\
\text { fracture energy, vibration } \\
\text { amplitude and friction work. }\end{array}$ \\
\hline $\begin{array}{l}\text { Kim et al. } \\
{[14]}\end{array}$ & $\begin{array}{l}\text { Al 5754; spot } \\
\text { weld }\end{array}$ & $\begin{array}{l}\text { Constant coefficient of } \\
\text { friction }\end{array}$ & $\begin{array}{l}\text { Surface friction (proportional to } \\
\text { friction force and slip velocity) } \\
\text { and consequent bulk plasticity }\end{array}$ & Johnson-Cook deformation model. & $\begin{array}{l}\text { Temperature, workpiece } \\
\text { velocities }\end{array}$ \\
\hline $\begin{array}{l}\text { Doumanidis } \\
\text { and Gao } \\
{[15,16]}\end{array}$ & $\begin{array}{l}\text { Al } 1100 \text { foil \& } \mathrm{Al} \\
6061 \text { sheet; US } \\
\text { consolidation }\end{array}$ & $\begin{array}{l}\text { Analytical model and } \\
\text { calibrated coefficient of } \\
\text { friction }\end{array}$ & $\begin{array}{l}\text { Mechanical analysis only, as } \\
\text { precursor to subsequent thermal } \\
\text { simulation. }\end{array}$ & $\begin{array}{l}\text { Constant (ambient) temperature; } \\
\text { bilinear elastic-plastic model with } \\
\text { kinematic hardening }\end{array}$ & $\begin{array}{l}\text { Workpiece velocities, } \\
\text { temperature-time histories }\end{array}$ \\
\hline $\begin{array}{l}\text { Zhang and } \\
\text { Li [17-19] }\end{array}$ & $\begin{array}{l}\text { Al } 3003 \text { foil; } \\
\text { ultrasonic } \\
\text { consolidation }\end{array}$ & $\begin{array}{l}\text { Two cases: constant and } \\
\text { temperature-dependent } \\
\text { coefficients of friction, } \\
\text { calibrated via separate } \\
\text { experiments. }\end{array}$ & $\begin{array}{l}\text { Two cases: friction only (from } \\
\text { shear stress and sliding } \\
\text { distance), and friction plus } \\
\text { plastic heating. }\end{array}$ & $\begin{array}{l}\text { Two cases: constant (warm) yield- } \\
\text { stress, and temperature-dependent } \\
\text { yield stress }\end{array}$ & No temperature validation \\
\hline $\begin{array}{l}\text { Lee et al. } \\
{[20]} \\
\text { Lee and Cai } \\
{[21]}\end{array}$ & $\begin{array}{l}\mathrm{Al} \text { and } \mathrm{Cu} \\
\text { foil/sheet; multi- } \\
\text { sheet / dissimilar } \\
\text { spot welds }\end{array}$ & $\begin{array}{l}\text { Constant coefficient of } \\
\text { friction, adjusted by } \\
\text { material and joint } \\
\text { configuration. }\end{array}$ & $\begin{array}{l}\text { Two cases: friction only, and } \\
\text { friction plus plastic heating. }\end{array}$ & $\begin{array}{l}\text { Cyclic plasticity combining } \\
\text { isotropic and kinematic hardening, } \\
\text { with temperature-dependency. }\end{array}$ & $\begin{array}{l}\text { No direct validation, only } \\
\text { weld surface profiles, and } \\
\text { indicative final temperatures } \\
\text { from other work. }\end{array}$ \\
\hline $\begin{array}{l}\text { Chen et al. } \\
{[22-25]}\end{array}$ & $\begin{array}{l}\text { Commercial } \\
\text { purity Cu \& Al } \\
\text { foil; dissimilar } \\
\text { spot welds. }\end{array}$ & $\begin{array}{l}\text { Not stated - heat input } \\
\text { independent of time, so } \\
\text { assume constant } \\
\text { coefficient of friction or } \\
\text { shear stress. }\end{array}$ & $\begin{array}{l}\text { Surface friction and plastic } \\
\text { deformation. }\end{array}$ & $\begin{array}{l}\text { Two cases: Johnson-Cook model } \\
\text { with non-ultrasonic literature data; } \\
\text { and modified J-C model calibrated } \\
\text { to tensile tests, and compression } \\
\text { tests with ultrasonic vibration. }\end{array}$ & $\begin{array}{l}\text { Temperature, sample } \\
\text { deformation }\end{array}$ \\
\hline $\begin{array}{l}\text { Shen et al. } \\
{[26]}\end{array}$ & $\begin{array}{l}\text { Cu sheet; spot } \\
\text { weld (battery tab- } \\
\text { bus) }\end{array}$ & $\begin{array}{l}\text { Temperature-dependent } \\
\text { coefficient of friction }\end{array}$ & $\begin{array}{l}\text { Constant heat input per unit area } \\
\text { (calibrated using temperature } \\
\text { data) }\end{array}$ & $\begin{array}{l}\text { Cyclic plasticity combining } \\
\text { isotropic and kinematic hardening, } \\
\text { empirical ultrasonic softening, and } \\
\text { temperature-dependency. }\end{array}$ & $\begin{array}{l}\text { Temperature, weld zone } \\
\text { geometry }\end{array}$ \\
\hline $\begin{array}{l}\text { Ngo et al. } \\
{[27,28]}\end{array}$ & $\begin{array}{l}\text { Al; spot and seam } \\
\text { welds }\end{array}$ & $\begin{array}{l}\text { Assumed friction } \\
\text { conditions not stated. }\end{array}$ & $\begin{array}{l}\text { Friction and bulk plasticity as } \\
\text { functions of yield strength, } \\
\text { time-dependent weld area, and } \\
\text { welding parameters (downforce, } \\
\text { amplitude and frequency) }\end{array}$ & $\begin{array}{l}\text { Yield stress linear in temperature; } \\
\text { no strain-rate dependence }\end{array}$ & $\begin{array}{l}\text { Temperature (accuracy } \\
\text { sensitive to number of } \\
\text { locations measured) }\end{array}$ \\
\hline
\end{tabular}


The literature summarised in Table 1 shows that the prime objectives of all thermomechanical modelling are to predict the temperature history and heat generation as a function of process conditions, and in many cases the evolution of the state and shape of the deformation zone, and development of the full bond - though experimental validation is not always provided. Knowledge of the process conditions is then applied to interpret or predict other aspects of the process - for example: (i) an indication of the joint strength [11] or fracture energy [12,13]; (ii) the effect of the sonotrode knurl pattern on interface deformation and bond formation [21-25]; and (iii) grain size and microhardness in the weld zone [26].

The starting point for almost all models of the contact in USW in Table 1 is Coulomb friction, with a coefficient of friction calibrated in various ways. Zhang and Li devised separate friction experiments to calibrate the friction coefficient for Al foil in comparable conditions, initially at a constant temperature of $150^{\circ} \mathrm{C}$ [17], and then over the full temperature range using a Gleeble test machine [18] [19]. It remains an assumption that the friction conditions in the tests accurately represent those in USW, but direct measurements of transverse forces are not available, and would be complicated by machine inertia in any case. Coefficients of friction, either constant or temperature-dependent, are therefore treated in most cases as calibration values, adjusted to provide a heat input which is consistent with measured temperatures (since direct power histories are also unavailable). This approach to modelling the contact is pragmatic, and physically realistic in the early stages of asperity contact, but becomes questionable once full contact is established and bulk plasticity takes over. A related factor is the amplitude of oscillation, which is used in combination with the friction stress to calculate the frictional heating. Nominal machine values are routinely assumed to apply in the literature without comment, but there is a lack of experimental validation of actual displacement histories due to the small distances and high frequencies - this is discussed further in our model implementation below.

Fully coupled thermomechanical models predict the heat input to the weld via friction and plastic deformation, solving the temperature and deformation responses simultaneously, having imposed kinematic and frictional boundary conditions. The appropriate choice of constitutive response for hot plasticity in ultrasonic welding is particularly demanding. Conventional uniaxial hot flow stress models capture the temperature and strain-rate dependency of flow stress, with isotropic strain hardening (which steadily diminishes in all alloys as temperature increases) - a common approach (and assumption) being the use of the Johnson-Cook equation. But in USW, there are the added complications of kinematic hardening due to the cyclic deformation conditions, plus the phenomenon of ultrasonic softening in which high frequency cyclic oscillation leads to a further reduction in flow stress (sample data are discussed later). Different authors in Table 1 have allowed for different factors by making empirical modifications, with a few implementing responses that aim to capture all of the phenomena in USW $[21,25,26]$. Constitutive data for many alloys are relatively sparse or incomplete for conventional hot deformation in the temperature and strain-rate regimes of friction processing and even more so in the high frequency cyclic domain of USW. Since the heat generation in USW is closely coupled to the plastic response, the limitation of the input plasticity data on thermomechanical modelling must be recognised - and sets a limit on the precision that can be realistically expected, however sophisticated the rest of the model implementation.

USW of sheet metal does have the computational advantage of applying only small displacements compared to the sheet thickness. This avoids the computational challenge of handling large deformations, which typically require computationally intensive Arbitrary Lagrangian-Eulerian (ALE) approaches. Nonetheless, most of the previous approaches to modelling USW still lack computational efficiency, by attempting to model the 1000s of cycles taken, due to the very high frequency of the 
process. Several authors comment on this problem, and adapt their implementation to improve computational efficiency - for example, using explicit analysis to predict the frictional heat flux, which then served as an input to an implicit analysis of the entire process [20], and the common techniques of limiting the model size and grading the mesh [22-25], or simplifying to 2D [21]. Some authors have sought computational efficiency by making simplifications that avoid the challenges of high frequency and thermomechanical coupling completely, while capturing some of the essential mechanical chacateristics. Example approximations are neglecting the transverse displacement altogether, and incorporating its effect via a calibrated heat input, or through applying ultrasonic softening to the constitutive response in a more conventional uniaxial hot compression model of the process $[10,11,26]$. Ngo et al. $[27,28]$ bypassed finite element methods by treating the problem with a one-dimensional heat conduction model, using difference methods and an optimisation algorithm to adjust the heat transfer coefficient to the tool, and a time-dependent heat generation, to give the best fit to recorded thermocouple histories. This may be a fast calculation, but lacks predictive capability, and the same results could in any case be readily achieved by thermal FE analysis with more realistic 3D heat transfer.

In summary, the approach in this paper addresses the modelling issues in USW in a number of different ways to the work summarised in Table 1:

- the model is limited to the latter stages of welding, when sliding friction has ceased, and bulk plasticity governs the heat dissipation and the temperature field at the interface - for the reason that the Manchester experiments [6,7] showed that a minimum time was needed to make a sound weld, but the duration of the subsequent hold time influenced the weld strength and microstructural evolution (such as interface intermetallic compounds), with this regime being the focus of our work.

- hot plasticity data for USW is not routinely available, nor is the Johnson-Cook formulation reliable for the friction processing regime - so conventional hot forming data has been gathered from the from literature for Al-6111, and curve-fit to capture the relevant temperature and strain-rate dependence, with an empirical allowance made for ultrasonic softening, guided by the literature. Constitutive plasticity data sets the greatest limit to the accuracy of the predictions, so we take a pragmatic "engineering” approach and apply a \% softening factor to give upper and lower bounds on the flow stress, and assess the sensitivity of the heat input to the choice of bounds.

- a similar pragamatic approach is taken to the effect of amplitude: experimentally observed average values are used rather than nominal machine values, but upper and lower bound values are applied in the model to test the sensitivity of heat generation to amplitude.

- the power history was independently inferred from thermocouple data and a thermal model, and this thermal model is imported into the deformation model - but the power history may then be validated by comparison with the heat generation predicted from the deformation model.

Computational efficiency is approached by a completely new approach, by recognising that the deformation behaviour and heat flow evolve on very different time scales. The first part of the method is to calibrate a thermal model for the process against thermocouple data, to predict the temperature field throughout, and provide an independent calibration of the power history at the workpiece (during initial frictional contact and subsequent bulk plasticity). The computational efficiency then comes from the second part of the method, in which heat generation by deformation is evaluated by taking a 'snapshot' of a single oscillation cycle, and only repeating this complex analysis 
at discrete intervals, while running the much simpler thermal model continuously. The method has been successfully applied in the context of friction stir spot welding (FSSW) [29].

The basic procedure in the context of USW is shown in Figure 1. As noted previously, the deformation modelling is limited to the second phase of welding, after complete contact is established. So the power input is initially determined from the calibrated thermal model (Figure 1a). For each 'snapshot' deformation analysis, the temperature field from the thermal model (Figure 1b) is imposed as an input to the deformation model, consisting of a single cycle of deformation applied sinusoidally (Figure 1c), predicting the consequent heat generation rate distribution and average instantaneous power.

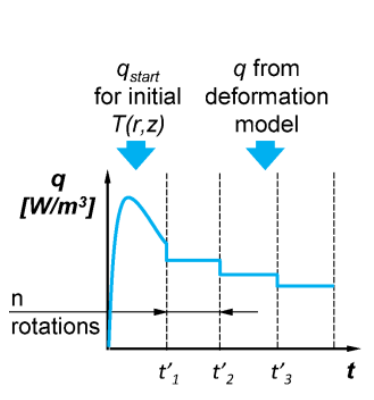

(a)

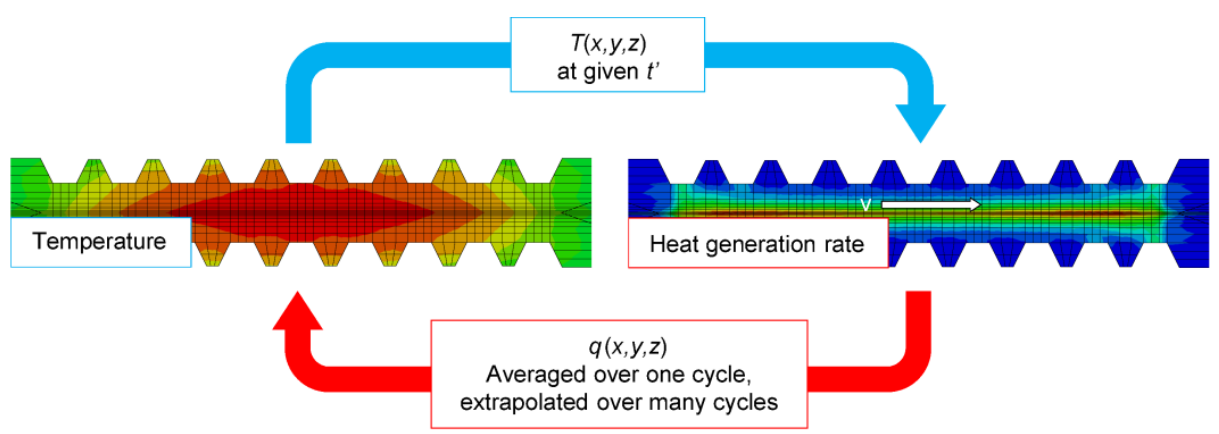

(b) (c)

Figure 1. Computationally efficient analysis of ultrasonic welding: (a) power input history; (b) thermal model, running continuously; (c) deformation model, applied for single cycles of the process, at discrete intervals.

The analysis is presented in two stages. First, the thermal and deformation models are uncoupled, comparing the thermocouple-inferred heating rate with the values output from the deformation 'snapshot' models, to test the sensitivity to model assumptions (particularly the constitutive data), when applied to USW of Al 6111 in three material combinations. Second, a fully coupled model is run as a proof of concept, with the heat input being derived from plasticity throughout the analysis (as illustrated in Fig.1a), for an Al-steel weld.

\section{Experimental work}

The experimental work used to calibrate the models was conducted at the Manchester University Materials Science Centre [1-7, 30-33]. The nominal composition (wt\%) of the 6111-T4 Al alloy used in all welds was: $\mathrm{Al}-0.58 \mathrm{Mg}-0.82 \mathrm{Si}-0.59 \mathrm{Cu}-0.2 \mathrm{Mn}-0.26 \mathrm{Fe}$ ). This was welded to itself, and to DC04 steel (Fe-0.08C-0.4 Mn) and Ti alloy Ti6Al4V (Ti-6.15Al-4V-0.3Fe). 100mm $\times 25 \mathrm{~mm}$ coupons were prepared, with thicknesses of $0.93 \mathrm{~mm}$ in $6111 \mathrm{Al}, 0.97 \mathrm{~mm}$ in DC04 steel, and $1 \mathrm{~mm}$ in Ti6Al4V. All joints were created in a lap configuration, with the weld located at the centre of a $25 \mathrm{~mm}$ overlap.

All welds were made with a Sonobond Ultrasonic MH2016 dual head spot welding machine. The constant frequency is $20.5 \mathrm{kHz}$, output using IGBT semi-conductor devices and converted to mechanical vibration with a piezoelectric transducer, amplified and transmitted to the workpiece via wedges and reeds. An external air compressor provides a constant clamping pressure through the reeds and tips to the workpiece. The two sonotrode tips vibrate linearly with opposing phases. Clamping force is set by the operator, depending on the tool geometry and the materials - here we used $1.4 \mathrm{kN}$ for Al-steel and Al-Ti welds, and $1.9 \mathrm{kN}$ for Al-Al. The nominal power was $2.5 \mathrm{~kW}$ for 
all welds., while the welding time and an adjustable impedance determine the energy delivered for a given nominal weld power. Extensive previous studies assessed the influence of these welding parameters on the mechanical properties of the joints, including load and fracture energy from lap shear tests, weld cross-sectional area, and sheet thinning. An optimium set of parameters that produced sound welds was established for each combination of joined materials [30,31], and these conditions were applied in this work. Welding times from 0.25-3s were used for Al-steel welds, and single welding times of $0.6 \mathrm{~s}$ and $1.2 \mathrm{~s}$ respectively were used for $\mathrm{Al}-\mathrm{Al}$ and $\mathrm{Al}$-Ti welds.

The Sonotrode tool profiles used for gripping the workpieces in $\mathrm{Al}$ and in steel/Ti respectively are shown in Fig. 2. The deformation model requires the history of tool indentation, in order to accurately reproduce the evolution of the workpiece geometry. In most welds, the depth of tip penetration into the workpiece was measured with 3D surface profiling with a laser profilometer, and the tool indentation as a function of time was measured from images of the weld cross-sections [30,31]. Data were obtained for both sheets, for each of the material combinations, and for any instant during welding the indentation of the workpieces was interpolated linearly. Data were not available for the Ti6Al4V in the Al-Ti welds, but the indentation was assumed to be identical to that recorded for Alsteel, as in both cases the tool designs and welding parameters were identical, and most of the plastic deformation took place in the top $\mathrm{Al} 6111$ sheet.

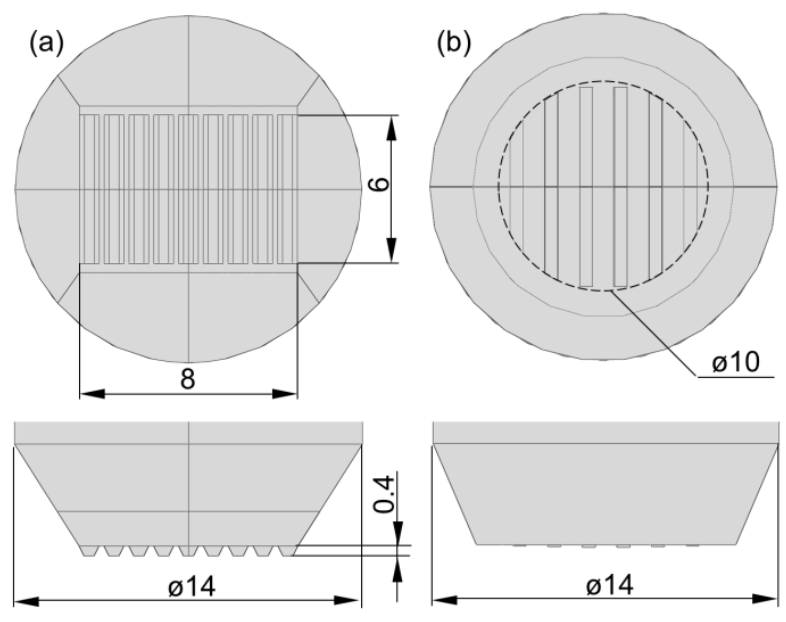

Figure 2 Sonotrode welding tip geometries for: (a) aluminium;

(b) steel and titanium (dimensions in mm) (after [31]).

As noted previously, the finite element deformation model is applied after full contact has been established, and does not describe the initial frictional stage of the process. The duration of this initial stage was inferred experimentally, using the average time necessary to reach the maximum strength in a lap shear test - in $\mathrm{Al}-\mathrm{Al}$ this was $0.4 \mathrm{~s}$, and in $\mathrm{Al}-\mathrm{Ti}$ and $\mathrm{Al}-\mathrm{Fe}$ it was $0.8 \mathrm{~s}$ and $1 \mathrm{~s}$ respectively [1,3,4,30-33]. The bond area was measured from images of weld fracture surfaces, and was approximated in the model by a rectangle of fixed dimensions, given in Table 2.

\begin{tabular}{ccc} 
Material combination & Interface width [mm] & Interface length [mm] \\
\hline Al 6111-Al 6111 & 6 & 8.8 \\
Al 6111 - steel DC04 & 5.4 & 8.2 \\
Al 6111 - Ti64 & 5.4 & 8.2
\end{tabular}

Table 2 Bond area dimensions for each material combination 
The vibration amplitude was measured experimentally for short duration welds (up to 0.25s) in Al-steel using a SIOS SP-S LSV Series laser vibrometer [31]. There was some scatter in the data, but the amplitude reached a quasi-steady-state value of $5.5 \mu \mathrm{m}$. In a separate study of Al-Mg USW using the same machine [30], the steady-state amplitude was found to be $6.5 \mu \mathrm{m}$. Values of 5.5 and $6.5 \mu \mathrm{m}$ were therefore used in the model as upper and lower bounds for the Al-Al and Al-Ti welds, for which no measurements of vibration amplitude were made.

Temperature histories were recorded with standard miniature $0.5 \mathrm{~mm}$ diameter $k$-type thermocouples with a stainless steel sheath, positioned at the weld centre, touching the weld interface. Temperature measurements were recorded at $100 \mathrm{~Hz}$ using a National Instruments datalogger [30]. The experiments conducted to develop the thermal model [8] used up to 5 welding times, and the heating stages of the temperature histories over-lapped closely between different welds, demonstrating the reproducibility of the temperature data recorded at the weld centre. In the Al-steel welds, thermocouples were also located at the edge of the weld contact area, but the thermocouple histories were less reproducible, suggesting that the thermocouples moved during welding. This data only therefore gave an approximate estimate of the lateral temperature distribution in both experiment and model. The reproducibility of the thermocouple data at the weld centre gave confidence in the calibration of the thermal model ([8], summarised below). Only the longest weld time in each material combination was selected for the current analysis, as this automatically covers the conditions for shorter weld times.

\section{Thermal model}

The thermal model has the objectives of inferring the power history from thermocouple data, and predicting the temperature field for any weld time as input to the deformation model. The model and its validation is described in full elsewhere [8]; the key features relevant to the deformation model of USW are summarised below.

Figure 3 shows the geometry and mesh of the three-dimensional FE model. The weld geometry is symmetrical about a longitudinal vertical plane, so only half of the weld needs to be modelled. The insets to the figure show details of partial cross-sections of the weld region, showing the profiling and dimensions of the tools. The sheet thicknesses were adjusted according to the material combination in the weld. 8-node brick (DC3D8) and 4-node tetrahedron (DC3D4) linear heat transfer elements were used in the thermal model. The model included temperature-dependent specific heat, thermal conductivity, and density (Appendix I).

Because of the progressive tool indentation, each deformation model is a "snap-shot", along with its associated temperature field, with a slightly different geometry. The temperature fields, and hence the thermal models which generated them, also needed to include the progressive tool indentation. Since the geometry in each heat transfer model changes, the thermal fields exported at different weld times (and different indentation depths) were generated by separate thermal models. In each model, the tool indentation was kept constant through a complete thermal analysis, starting again from $t=0$, with the geometry being defined by the indentation depth of the subsequent snapshot deformation model, to which the temperature field is exported. Hence each thermal model required a slightly different power history (from $\mathrm{t}=0$ ), calibrated separately, in order to predict the temperature field accurately at the time of each deformation step (using the thermocouple at the centre of the interface). Despite the assumption of a fixed tool indentation in the thermal model, the approach described gives reasonable temperature predictions, as the tool indentation was found to have a minimal influence on the temperature field, provided that the total heat input is always calibrated (see [34] for details). 


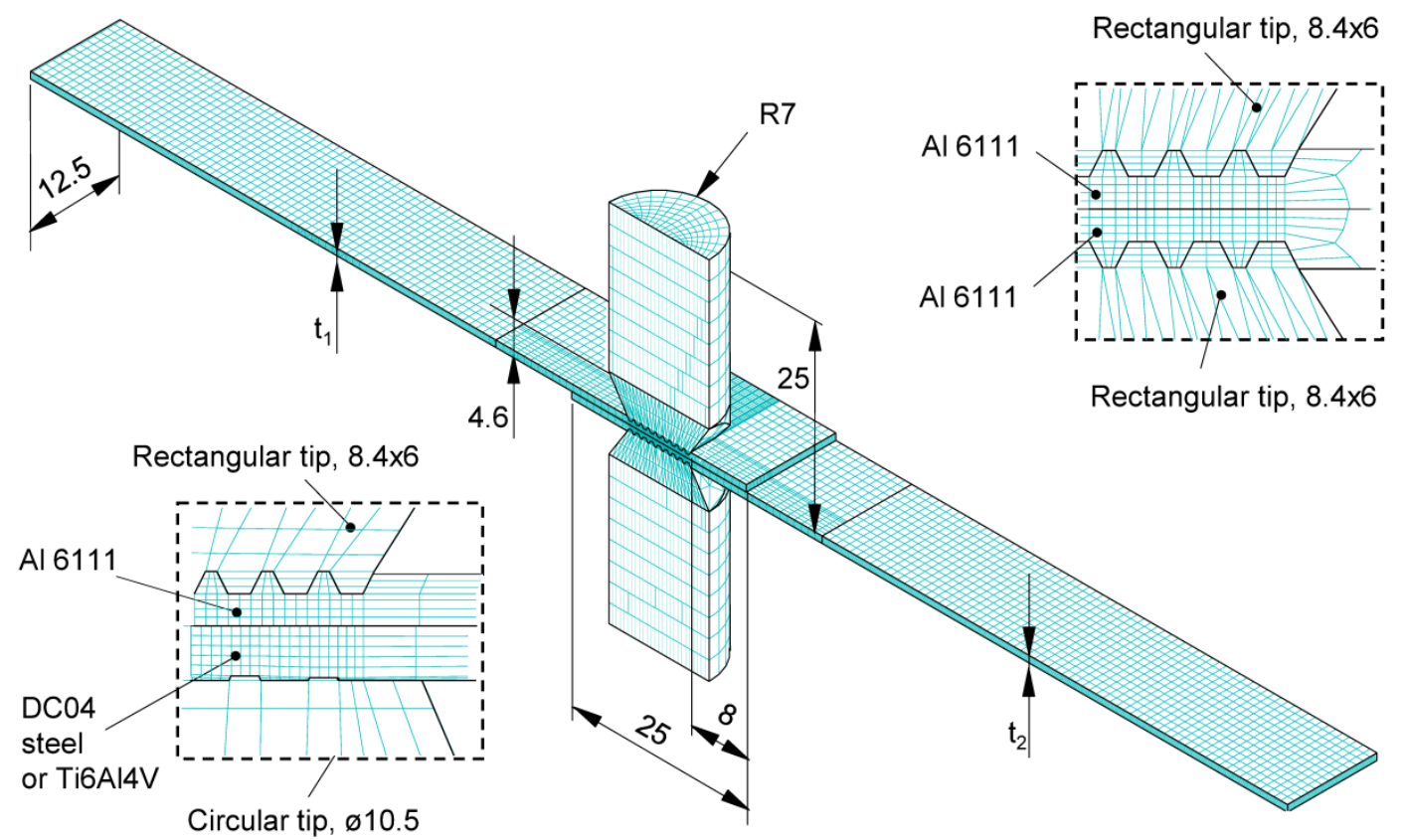

Figure 3 Thermal finite element model: geometry and mesh (dimensions in mm); inset: details of part of weld zone (white dashed area in main figure)

For computational efficiency, the surfaces in contact with the air were treated as insulated, due to the low heat transfer coefficient to air, the short cycle time, and the relative remoteness of these surfaces to the thin weld region. The metal-to-metal contact conductance between the workpieces is assumed to be perfect, given the high clamping pressure between the sonotrodes, and the initial surface sliding between the workpieces. Outside the weld zone the workpieces are not pressed together, and often separate slightly as the weld is produced, so this region was considered to have an insulated thermal boundary. Finally, the contact between the workpieces and the moving tools will also be an intimate contact, again modelled assuming perfect heat transfer.

Initial heat generation is by sliding at the interface, whereas after full contact is made, the same oscillating displacement is accommodated by plastic deformation, and the heat input will depend in a more complex way on the evolving temperature field and the constitutive response of the alloys. But as the deformation layer is relatively thin, the heat flux in the thermal model was assumed to remain uniform and was applied only over the contact area, throughout the whole weld cycle. Testing this assumption is one aspect of modelling the coupled thermal and deformation problems.

A full predictive capability of the thermal model requires either independent measurement of the power, which is not available for standard USW machines, or a first-principles thermomechanical model based on constitutive data for both frictional and fully bonded phases. So in this work, the net power input $q(t)$ was adjusted empirically with a piece-wise linear variation, in steps of order of 0.05$0.1 \mathrm{~s}$, until the model matched the temperature history recorded by the centre thermocouple. A $q(t)$ curve was calibrated for each material combination, using the weld of longest duration in each case. This single fitted curve may then be applied for welds of shorter durations, provided all other process conditions are unchanged, simply by truncating the heat input at the appropriate weld time. The resulting calibrated power histories are shown in Fig. 4. These show heating patterns that are consistent with an initial ramp-up to a peak, due to growth of the contact area under frictional sliding, followed by a steady decay of the heat input rate due to progressive material softening. 


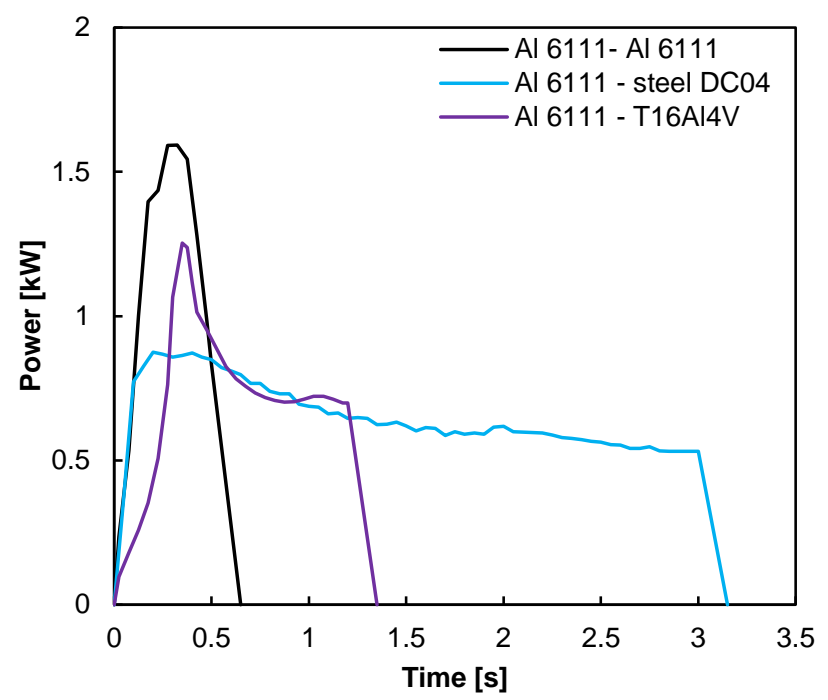

Figure 4 Power-time histories $q(t)$, inferred from fitting the model to thermocouple data at the weld centre, for each of the material combinations.

The measured and predicted temperatures are shown in Figure 5, confirming how closely the temperature is followed by calibrating $q(t)$ as far as the temperature peak, which is the part of the curve of interest for deformation modelling. Even so, in the cooling stage (when $q=0$ ), there is only a small discrepancy, which validates the use of the simple thermal boundary conditions between the workpiece and sonotrodes and the surrounding air. The accuracy of the thermal model was also confirmed by comparing predictions of the calibrated model with the temperature data for shorter duration welds, and for thermocouples situated at other locations than the weld centre [8].

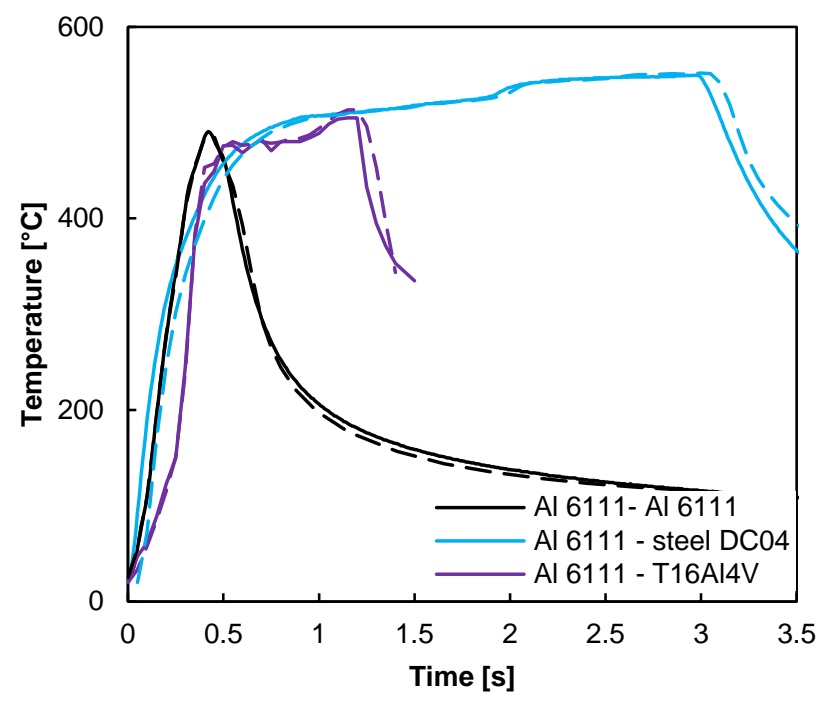

Figure 5 Experimental temperature histories at the weld centre (solid lines) and calibrated model prediction (dashed lines), for each of the material combinations.

\section{Deformation model}

The deformation model aims to identify the conditions under which the workpiece materials are deforming, and to relate the material constitutive data directly to heat generation in ultrasonic welding. Even though the deformation essentially occurs in plane strain with transverse oscillation, a full three-dimensional analysis is required. This is because the 3D heat flow creates a temperature gradient across the workpiece, so the heat generation conditions vary over the whole interface. 
Figure 6 shows the deformation model geometry, which is identical to the workpiece material in the thermal model. Eight-noded thermally coupled brick, trilinear displacement and temperature elements (C3D8T) were used for meshing the workpieces. The element size was optimised in a sensitivity study, and a total number of approx. 15000 elements, with $20 \mu$ m-thick elements at the interface, provided the best compromise between accuracy and computation time [34].

The bonded area was simplified to a rectangle, with the dimensions in each case determined experimentally, as in Table 2. At the interface, the workpiece nodes are tied, with identical translational and rotational motion on both faces of the joined surfaces (Fig. 6). Similarly, the nodes are tied across both tool-workpiece interfaces, since mechanical interlocking, coupled with a high friction coefficient, effectively results in sticking conditions. The shapes and dimensions of the toolworkpiece interfaces are shown in Fig. 6, taken from experimental data. Each snapshot analysis uses the appropriate indentation depth for the elapsed weld time, as interpolated from experimental data, discussed earlier.

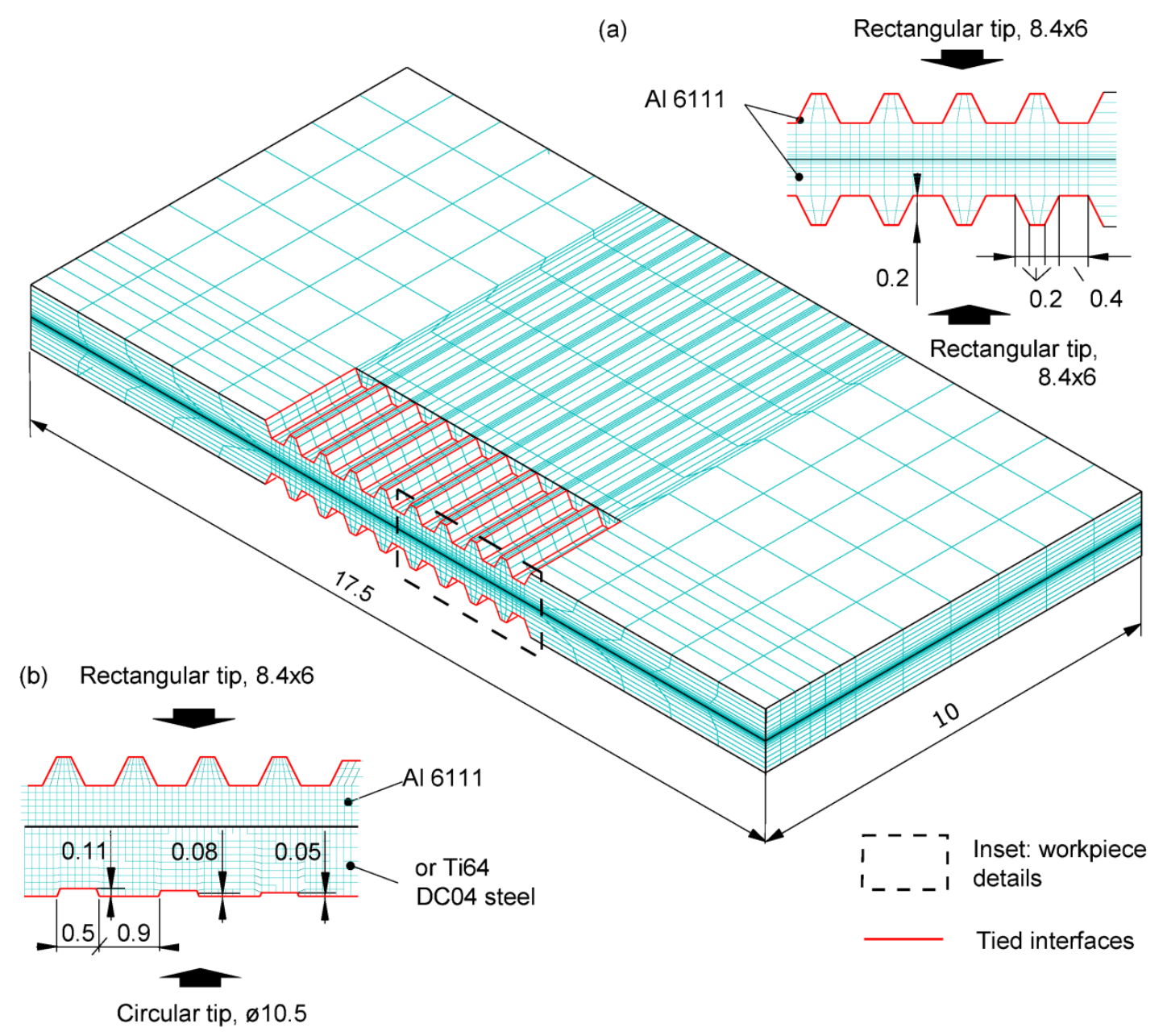

Figure 6 Deformation model geometry, mesh, and interface constraints for:

(a) Al 6111-Al 6111 welds; (b) Al 6111-Ti6Al4V and Al 6111-DC04 steel welds.

(Dimensions in $\mathrm{mm}$ )

A concentrated vertical force, as measured experimentally for each case (section 3), was specified on each of the tools. Since the tools are rigid, the forces are evenly distributed over the tool-workpiece interfaces. Tool rotation was constrained, but vertical displacements of the tools, and all degrees of 
freedom of the workpieces, are unconstrained. Each tool has a cyclic sinusoidal displacement specified in the horizontal direction, with a frequency of $20.5 \mathrm{kHz}$. Oscillation amplitudes measured experimentally were $5.5 \mu \mathrm{m}$ in $\mathrm{Al}-$ steel welds, and $6.5 \mu \mathrm{m}$ in $\mathrm{Al}-\mathrm{Mg}$ welds, so these measured values served as lower and upper bounds for the $\mathrm{Al}-\mathrm{Al}$ and $\mathrm{Al}-\mathrm{Ti}$ welds.

The temperature field was imported from the three-dimensional thermal model at a given instant, and assumed to be unchanging throughout each snapshot analysis. The thermal model assumes a fixed indentation value, equal to the value at the end of a given elapsed welding time. So for each snapshot analysis, the thermal model was run, from time $t=0$, using the same indentation value as the deformation model. Note that this indentation is slightly different to that at the end of the completed weld, but the temperature field in each case automatically matches the thermocouple data, since the power history is adjusted to fit the temperature data.

\section{Material models}

The finite element model requires characterization of both elastic and plastic behaviour. Both are temperature-dependent, but the plastic constitutive response in particular requires careful attention to the effects of strain and strain-rate on flow stress - and in this context, there are further issues associated with cyclic deformation and ultrasonic frequencies.

Young's modulus and Poisson's ratio for the investigated materials were specified as temperaturedependent (see Appendix II), using material data from the literature [35-37]. DC04 steel was assumed to have elastic properties identical to a low carbon steel with a similar chemical composition, S10C [37]. For $\mathrm{Al} 6111$, experimental data were not available above $400^{\circ} \mathrm{C}$, and were linearly extrapolated up to the solidus temperature.

During ultrasonic welding, specimens undergo cyclic deformation, hence models of cyclic plasticity should be used to characterize the material behaviour. These may include both isotropic and kinematic hardening, capturing material behaviour such as the Bauschinger effect, cyclic hardening, twinning and ratchetting. All of these effects, however, are expected to weaken at high temperatures, e.g. where deformation takes place primarily at temperatures close to the solidus $\left(0.75-0.95 T_{\text {solidus }}\right)$, as is the case in USW of Al alloys. Ding et al. [38] tested Al alloy 6061-T6 (similar in composition to Al 6111), at room temperature and $150^{\circ} \mathrm{C}$. They showed that the difference between the yield stress in monotonic and cyclic loading was less than 5\%. It is assumed therefore that constitutive material data, obtained with monotonic loading, can be used in a simple, isotropic hardening plasticity model, for simulations of ultrasonic welding of $\mathrm{Al} \mathrm{6111.} \mathrm{Since} \mathrm{the} \mathrm{solidus} \mathrm{temperatures} \mathrm{of} \mathrm{steel} \mathrm{DC04} \mathrm{and} \mathrm{Ti6Al4V} \mathrm{are}$ much higher, the analysis shows that these materials undergo no plastic deformation during USW, other than pre-indentation by the steel tools. Hence in both cases the effects associated with cyclic plasticity can be neglected.

Most elastic-plastic analyses assume isotropic hardening of a material, and require full definition of yielding behaviour in the form of stress-strain curves. However, at temperatures of $300-550^{\circ} \mathrm{C}$ relevant to USW, Al alloys can be assumed to be perfectly plastic, with no strain hardening. So for simplicity, temperature-dependent, single-point yield behaviour can be assumed. Since at lower temperatures, there is some strain hardening, a representative strain value was needed to select a suitable single-point value to use at a given temperature and strain-rate. A nominal $10 \%$ strain was assumed as a representative average strain in the plastic zone during USW, though in practice heat generation is dominated by deformation at higher temperatures where the strain hardening is negligible. The flow stress at $10 \%$ strain was extracted from published stress-strain data, with the resulting datapoints shown in Figure 7a. 
Inconsistencies between constitutive data from different publications can be attributed to experimental errors and data sampling from stress-strain curves. In order to minimise the impact of these errors, a smoothed fit was developed to the collated yield data for both materials (Figure 7a). The model assumed a linear relationship between stress and $\log ($ strain-rate), following literature on similar alloys [39-41], with no strain hardening. At a given strain-rate, the best fit to the experimental data was obtained using a $4^{\text {th }}$ degree polynomial relation between flow stress and temperature, with the coefficients in the model optimised using the method of least squares. Beyond the highest temperature for the available experimental data, a linear drop to zero flow stress at the solidus was assumed, following Colegrove et al. [42]. Equations for the best fit curves to the collated experimental flow stress data are presented in Appendix III.
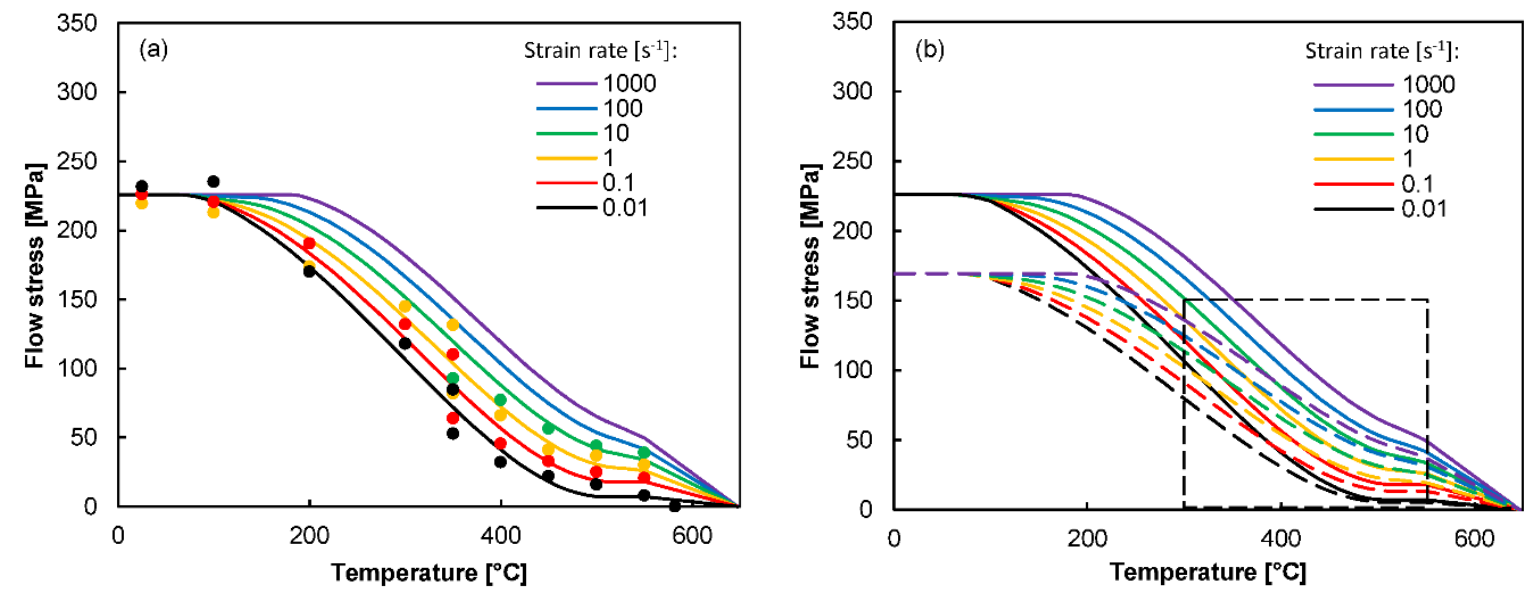

Figure 7 Constitutive yield stress-temperature data for Al-6111, for a range of strain-rates:

(a) best fit curves (solid lines) and underlying datapoints [43,44]; (b) the same data (solid lines) with an allowance for ultrasonic softening (dashed lines). [The dashed black box marks the ranges of $\sigma$ and

T shown enlarged in later material deformation maps, Figures 10-11.]

Any model of plastic deformation in ultrasonic welding of metals also has to consider softening due to the high frequency vibration, which is referred to as acoustic, or ultrasonic, softening. Several possible mechanisms of acoustic softening have been proposed, such as a superposition of the alternating ultrasonic stress on the static stress, localized heating at defect regions, or an 'activation' of dislocations by the preferential absorption of ultrasonic energy at lattice defects. The softening effect is instantaneous, no temperature change is observed, and a permanent change in material properties is recorded only at high vibration amplitudes [45-47]. Strain, strain-rate, temperature and frequency have a negligible influence on ultrasonic softening [45-48].

Several of these studies have investigated ultrasonic softening of aluminium alloys under conditions identical to those in the present study (temperature of $20-250^{\circ} \mathrm{C}$, oscillation frequencies of $20 \mathrm{kHz}$ and amplitudes of 5-6 $\mu \mathrm{m}$ ), showing a $12 \%$ to $24 \%$ reduction in yield stress of a 6000 -series $\mathrm{Al}$ alloy, measured respectively at yield and at $\varepsilon=1$. Commercially pure aluminium showed a $6 \%$ reduction in flow stress. Since the softening data for the exact alloys and conditions investigated in the present study are not available, the flow stress reduced by $25 \%$ was adopted as a lower bound, based on the largest reduction observed in similar alloys and conditions in the literature. The original data for flow stress uninfluenced by acoustic softening was then adopted as an upper bound. Figure 7(b) shows both sets of curves. Since the steel DC04 and Ti6Al4V undergo no plastic deformation, ultrasonic softening can be neglected for both materials. 


\section{Model validation}

The deformation model uses the deformation in a single cycle as a snapshot of the heat generation during continuous high frequency cycling. But as the process is continuous, the material state inherited from preceding cycles must be taken into account. Once the process is underway, the material will not be in a state of zero stress as it passes through the position of zero displacement at mid-cycle. So a single cycle of analysis would start from a completely unstressed state, giving an erroneous result. This issue was resolved by running a small number of "bedding in" cycles at the start of each simulation. A study was undertaken to find the minimum number of additional cycles needed to give a steady-state condition. The tool force amplitude, energy generated per cycle, and residual stress were used as indicators of the steady-state. The study was repeated for all material combinations. The results showed that a single additional cycle was sufficient to give a stable value of heat generation, so the second of two cycles was used in all the analyses.

A second validation check examined the local peaks in strain and heat generation predicted at the edges of the interface. This was a numerical artefact caused by the nodes on both sides of the joined surfaces being constrained to have equal motion. It was concluded that the influence of these singularities could be neglected, as in all cases their contribution to the total plastic dissipation was less than $5 \%$.

\section{Results}

The models for all three combinations were run with both upper and lower bounds for the constitutive data (Figure 7b). In all cases, the prediction of net heat generation showed best agreement if the lower bound (ultrasonically softened) data were used. For the Al-DC04 weld, the amplitude applied in the model was that measured experimentally, $5.5 \mu \mathrm{m}$. In the other two cases, upper and lower bound values were used, $5.5 \mu \mathrm{m}$ and $6.5 \mu \mathrm{m}$ (as noted above).

For the case of Al-Al USW, experiments showed that the joint quality quickly deteriorates with longer weld times, due to significant sheet thinning. The maximum weld duration was only $0.6 \mathrm{~s}$, so the window within which the current deformation model could be run was very narrow, since the model required the bond to be fully developed, which in this case took about 0.4s. The Al-Al weld was therefore only modelled at a single time. Figure 8a shows the predicted heat generation using the upper and lower bound displacements, superimposed on the power history inferred from the thermal model. The agreement is good, though limited to a single time during welding, demonstrating the potential for predicting heat generation directly from a kinematic description of the welding process and the constitutive behaviour of the material. Furthermore, analysis of a single cycle appears to be sufficient to capture the heat generation at any instant in this high frequency process, greatly improving the computational efficiency.

The dissimilar material combinations provide a greater test of the model's capability to predict the evolution of heat generation throughout the weld time. Sheet thinning is less of an issue in $\mathrm{Al}$ 6111DC04 steel and Al 6111-Ti64 welds, hence the weld times are significantly longer than in the Al-Al joints. Figure $8 \mathrm{~b}$ shows the power predicted at three points in each weld cycle. The results again agree well with the reference power history, for both material combinations. The Al-Ti results, using upper and lower bounds for the amplitude, again fall on either side of the power inferred from the thermal model. The analysis of the dissimilar alloy welds therefore confirms that the proposed modelling method successfully predicts the heat generation in ultrasonic welding, and is computationally efficient. 

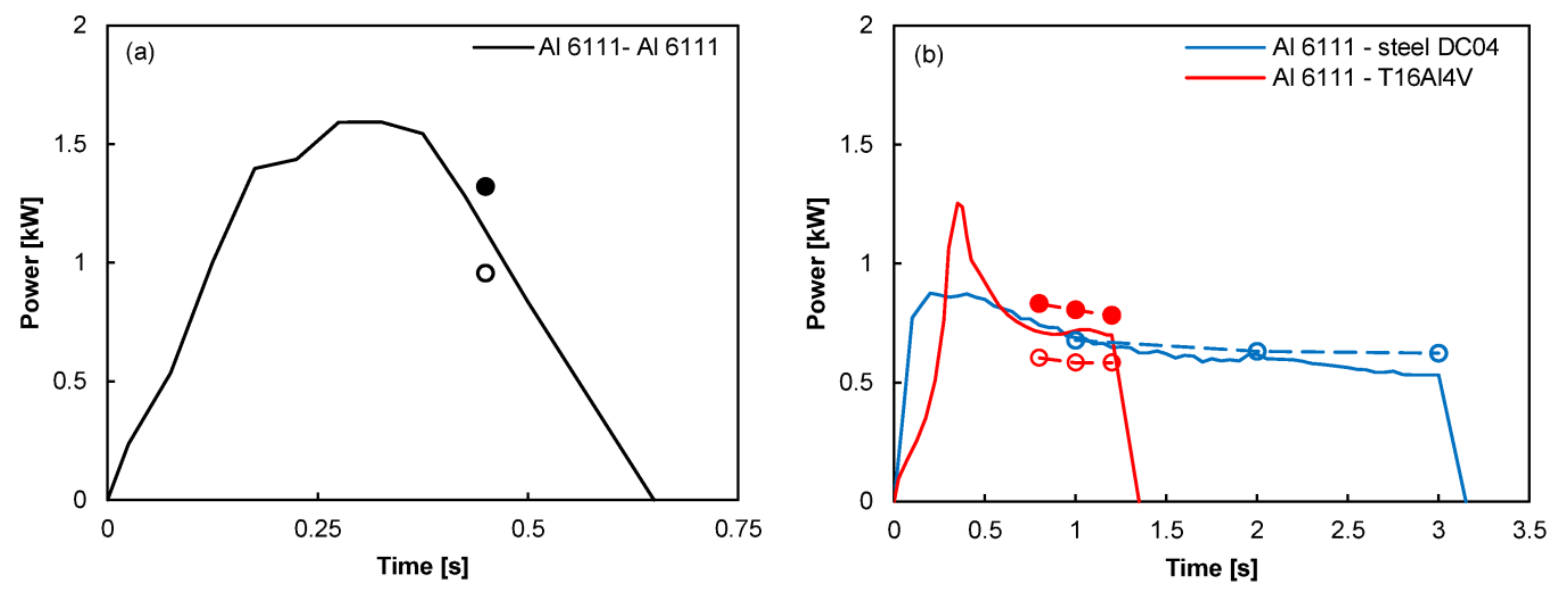

Figure 8 Predicted heat generation rate (datapoints) from the deformation model for: (a) Al 6111-Al

6111, (b) Al 6111 welded to DC04 steel and Ti64, compared with the power histories reverse engineered with the thermal model. For $\mathrm{Al}-\mathrm{Al}$ and $\mathrm{Al}-\mathrm{Ti}$, the model used upper and lower bounds in oscillation amplitude (closed and open circles, respectively); for Al-steel, a single measured amplitude was used.

\section{Material deformation maps}

An approach to visualising the material deformation behaviour was proposed by Colegrove and Shercliff in their work on CFD modelling of FSW [42,49]. Their method was to take the plot of flow stress as a function of temperature and strain-rate (as in Fig.7), and to overlay contours showing the dominant deformation regime via a form of probability density function, based on the proportion of the volume experiencing the underlying deformation conditions. Here the approach of Colegrove and Shercliff is modified, using a method applied by the current authors to FSSW [29]. In this case the constitutive data map has a superimposed set of contours displaying the amount of heat generated in relation to the underlying material conditions, rather than the probability that they will occur (by deformation volume). This modification was necessary, as otherwise the map is dominated by conditions in the bulk of the material away from the interface, which experiences relatively low plastic deformation and is characterized by low strain-rates and temperatures. These 'material deformation maps' help to understand the material softening behaviour, and have potential as a practical tool for selection of parameter windows, or identifying alloys with a desirable constitutive behaviour for friction joining.

In the numerical procedure, temperature and flow stress space is subdivided into a grid, giving discrete 'bins' of prescribed ranges, for example, at intervals of $1^{\circ} \mathrm{C}$ and $1 \mathrm{MPa}$. As the deformation model is run, conditions are sampled element-by-element, with the heat generated in each element in a fixed time interval being assigned to the appropriate 'bin', as determined by the average temperature and flow stress in the element. The total heat generated is evaluated over the weld, and the cumulative proportion of this total associated with each 'bin' is represented by colour contours superimposed on the flow stress map.

A typical contour map of equivalent plastic strain from the FE model is shown in Figure 9. This indicates that deformation is quite uniform across most of the welded interface. But note that this map is for a longitudinal vertical section through the centre of the weld. In the transverse direction, the temperature falls due to the $3 \mathrm{D}$ heat flow in the weld. Figure 10 shows the resulting material deformation map, for the whole weld volume, generated for the $\mathrm{Al}-\mathrm{Al}$ weld at $0.45 \mathrm{~s}$. The map shows that the deformation conditions fall in an elongated domain, with a characteristic strain-rate range of 
order $100-1000 \mathrm{~s}^{-1}$, and a temperature range from $350-500^{\circ} \mathrm{C}$. The strain-rate domain is largely dictated by the kinematic constraint of the imposed cyclic oscillation and the sample thickness, while the temperature gradient across the weld is heat flow limited. The map for USW differs from that observed in friction stir spot welding by Jedrasiak et al. [29]. In FSSW, the axisymmetric nature of the process, and the stick-slip conditions at the tool-workpiece interface, lead to a much more localized regime, with all the deformation typically taking place within a temperature range of $25^{\circ} \mathrm{C}$.

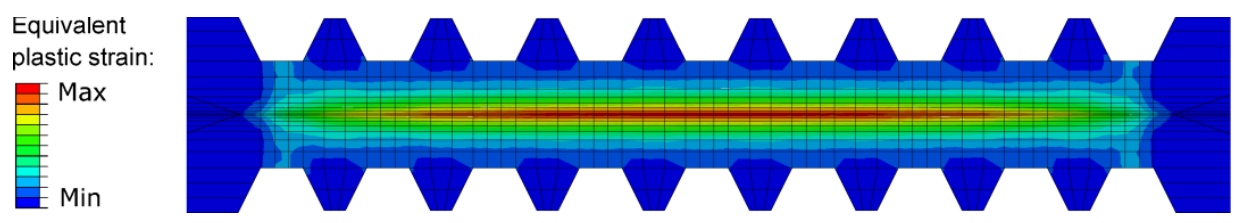

Figure 9 FE equivalent plastic strain in the $\mathrm{Al}-\mathrm{Al}$ weld at $0.45 \mathrm{~s}$.

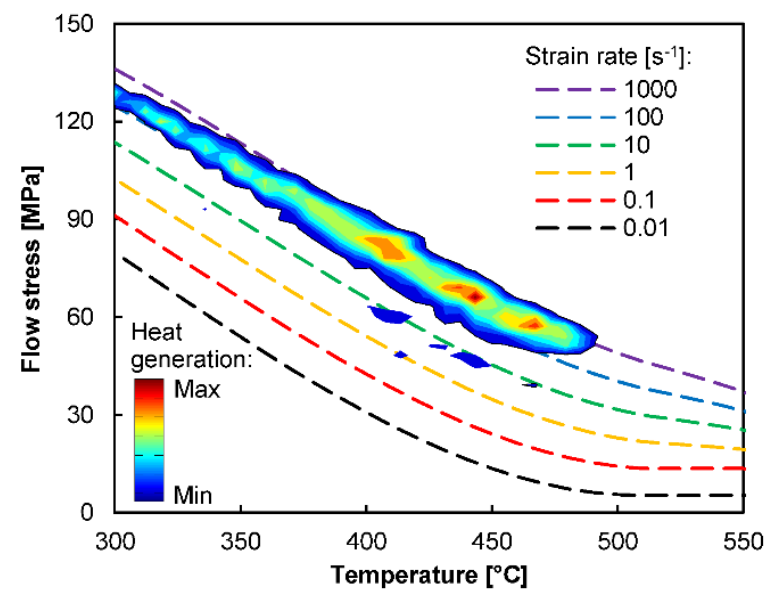

Figure 10 Material deformation map for $\mathrm{Al}$ 6111, over a magnified domain of stress and temperature (as indicated in Figure $7 \mathrm{~b}$ ), for the $\mathrm{Al}-\mathrm{Al}$ weld at $0.45 \mathrm{~s}$.

Similar material deformation maps were obtained for the deforming Al 6111 in the dissimilar alloy welds. Contour maps of equivalent plastic strain from the FE model for dissimilar alloy welds are shown in Figure 11. As in the case of the Al-Al weld, deformation is uniform across most of the welded interface, here however it takes place entirely in the top sheet, made of the softer Al alloy. Figure 12(a) shows the map for the Al-steel weld at 1s. Two maxima are visible, with the higher temperature peak corresponding to material close to the interface, while the lower temperature peak relates to a larger volume of material undergoing small strains, away from the interface. Most of the plastic deformation again takes place at strain-rates of the order of $1000 \mathrm{~s}^{-1}$, at temperatures in the range of $350-500^{\circ} \mathrm{C}$. Similar maps, generated for time instants later in the process, showed that deformation conditions steadily shifted to higher temperatures with increasing weld time. A material deformation map for $\mathrm{Al} 6111$ in the $\mathrm{Al}$-Ti weld at 0.8s is shown in Figure 12(b). The map is similar to that for Al-steel, as expected when the oscillation amplitude is similar, and all of the plastic deformation is accommodated in the $\mathrm{Al}$ sheet in both cases. The temperature range in the primary plastic deformation zone is lower at this instant during welding, ranging from $325-475^{\circ} \mathrm{C}$, and again increased steadily with the weld time. 


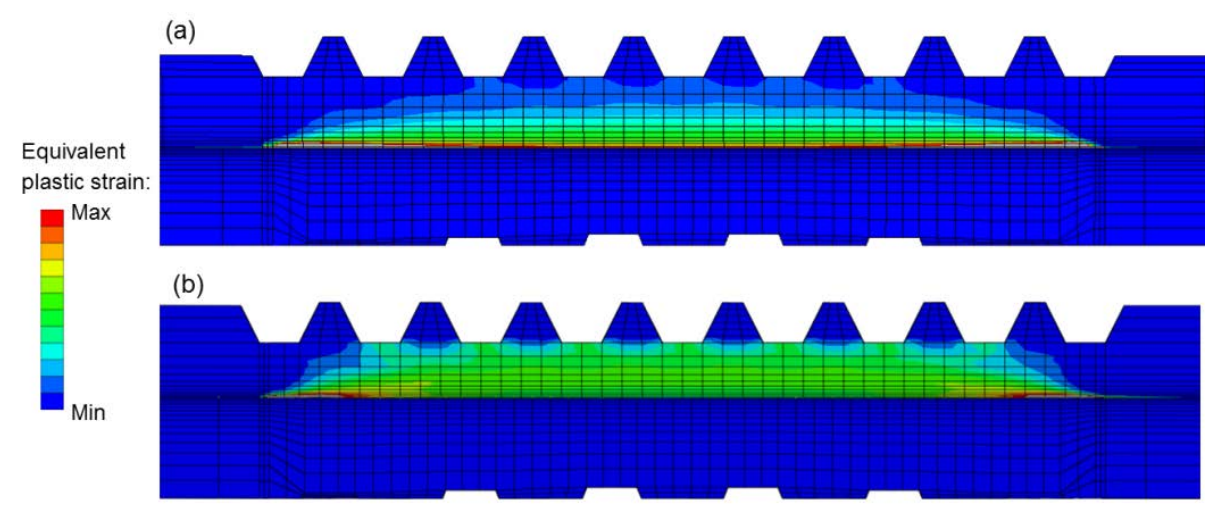

Figure 11 FE predicted equivalent plastic strain in the (a) the Al-steel weld at 1s; (b) the Al-Ti weld at $0.8 \mathrm{~s}$.
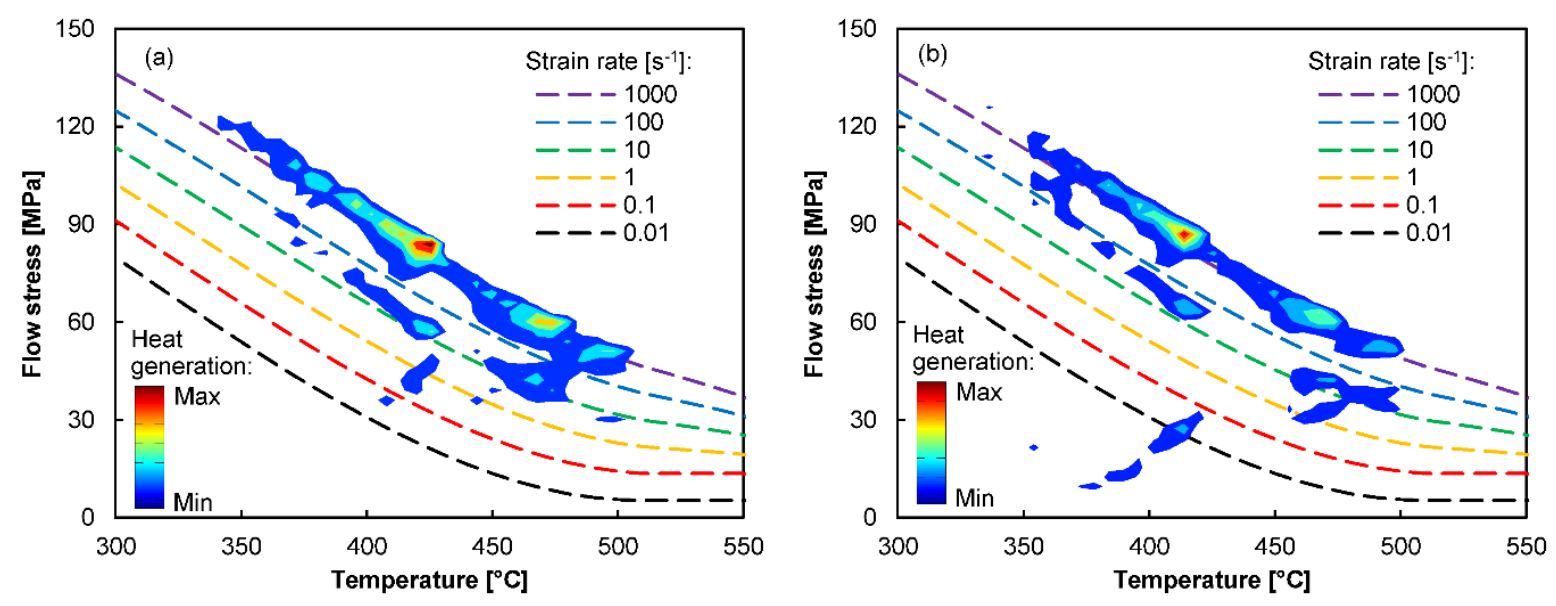

Figure 12 Material deformation maps for Al 6111, over a magnified domain of stress and temperature (as indicated in Figure 7b), for: (a) the Al-steel weld at 1s; (b) the Al-Ti weld at 0.8s.

\section{Full coupling of thermal and deformation models}

In a final test of the USW finite element models, 'two-way coupling' is introduced between the thermal and deformation models. By this we mean that the heat generation, once calculated from the deformation model, becomes the heat input distribution for the next increment of the temperature field, until the next deformation iteration, and so on. The proposed approach is here illustrated on one material combination, Al-steel, as a proof of concept, but the analysis can be extended to other material combinations.

The test case considered was the longest duration weld, between $\mathrm{Al}$ and steel, limited to weld times after the bond is fully developed ( $t>1 \mathrm{~s}$ ). For the initial stage, the thermal model was applied as before, using the reverse-engineered power input from thermocouple data. This provides the initial thermal field for the first snapshot using the deformation model at $t=1 \mathrm{~s}$. But after this point, the predicted heat input in the preceding snapshot is applied to the thermal model, until the time of the next deformation computation. Sequential alternating of the thermal and deformation models then continued until the end of the welding process $(t=3 \mathrm{~s}$ in Al-steel). Note that the spatial distribution of heat generation from the deformation model was simplified to a uniform surface heat flux at the joint interface, while keeping the net power unchanged. This is a reasonable approximation, as the model results showed that the horizontal distribution of heat generation was relatively uniform in all cases, while the through-thickness variation in heat generation has a small influence on the temperature distribution, as it occurs in a relatively thin layer near the interface. 
Figures 13 shows the predictions of heat generation rate and temperature, respectively, from the fully coupled USW model. Consider first the reference case (black curves). The heat generation predicted after $t=1 \mathrm{~s}$ closely matches the value at the end of the initial calibrated stage. This value of heat input is maintained from 1-2s, at which point the predicted temperature is too high. The next prediction of heat input, at $t=2 \mathrm{~s}$, is then lower. This suggests that there is a 'self-stabilising' effect, in which an over-prediction of temperature leads to a softer material response and a corresponding reduction in heat input. Conversely, if the predicted temperature is too low, the power input would rise. This is not a numerical artefact - it is essentially the physical phenomenon that stabilises many friction processes and avoids melting at the interface - i.e. as melting is approached, the drop in strength (and thus heat generation) usually makes it impossible to maintain the temperature gradient away from the interface, setting an upper limit on the temperature and keeping the interface in the solid state.

To test this observation, two further cases were simulated. The initial temperature histories for $t<1 \mathrm{~s}$ were artificially adjusted to be $10 \%$ higher and lower (red and green curves, respectively). Figure 13 shows that in both cases, the model is stable - the heat generation and temperature both converge back towards the reference case. The heat generation oscillates to either side of the true response, so it is stable but somewhat 'under-damped', while the temperature adjusts asymptotically over a characteristic timescale. Using more frequent analyses of the heat input would reduce the size of the oscillations. In conclusion, full coupling of the thermal and mechanical models works, and it is noteworthy that, once the initial thermal field is established, the power and temperature history are essentially predicted from first principles, direct from the constitutive behaviour and a kinematic description of the process.
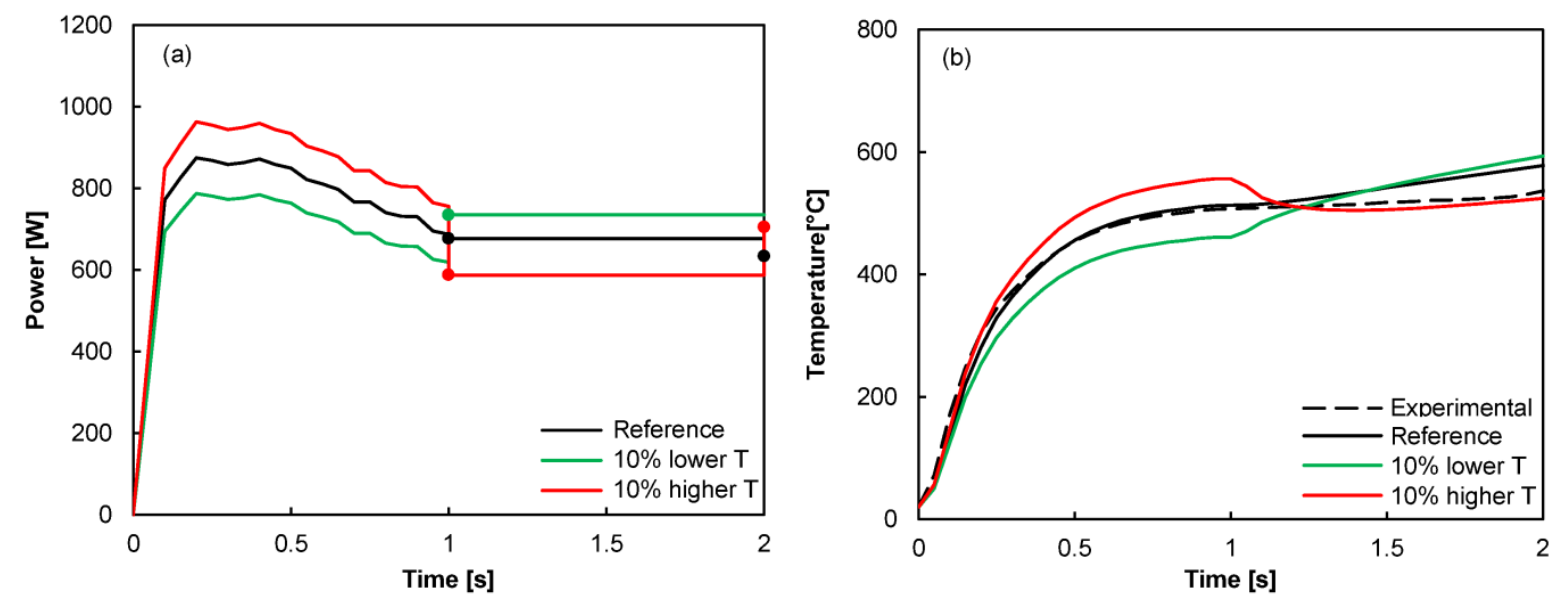

Figure 13 Predictions of fully coupled FE thermal and deformation models for the Al-steel weld: (a) heat generation rate (with datapoints showing the values found from the deformation model, and applied after $\mathrm{t}=1 \mathrm{~s}$ ); (b) temperature at the weld centre.

(The three test cases are explained in the text.).

\section{Model addendum: effect of shear banding}

As a footnote to the analysis, attention is turned briefly to the effect of tool alignment, which has received little attention in the literature. An important element of the USW process is the knurling of the tool tip, which has been shown to have significant influence on the in-process variables [22-25]. Chen et al.[5] found that at long welding times and significant tool indentations, tool misalignment was observed, and this caused the formation of shear bands, visible on an image of a weld crosssection (Fig. 14a). The deformation model was therefore run with the same oscillation amplitude, but with the tools misaligned by half the pitch of the grooves, as observed experimentally. This sheds 
some light on the origin of the shear bands, predicting stress localisation bands of a similar shape (Fig. 14b) between the peak of the knurl pattern. Figure 14c shows that the heat dissipation is more intense where the shear bands cross the weld interface. But the model also showed that tool alignment had virtually no influence on the net heat generation, which remained confined to a thin layer, or on the tool force cycle.

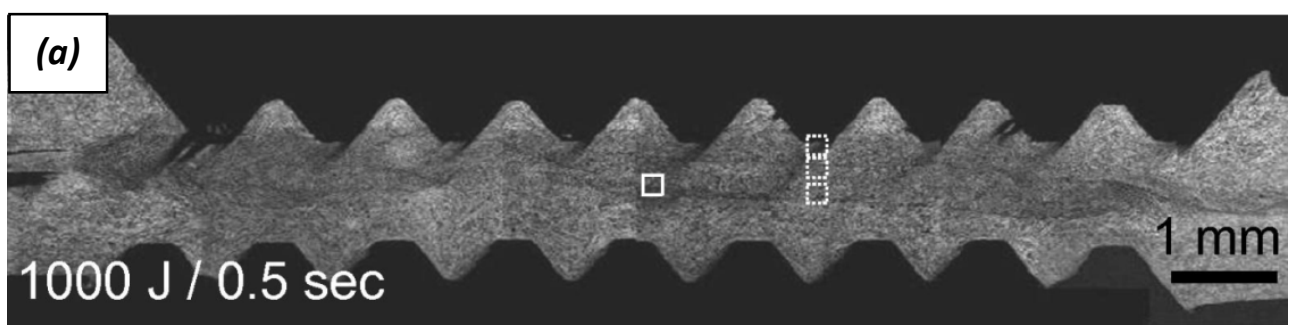

Von Mises

Stress:

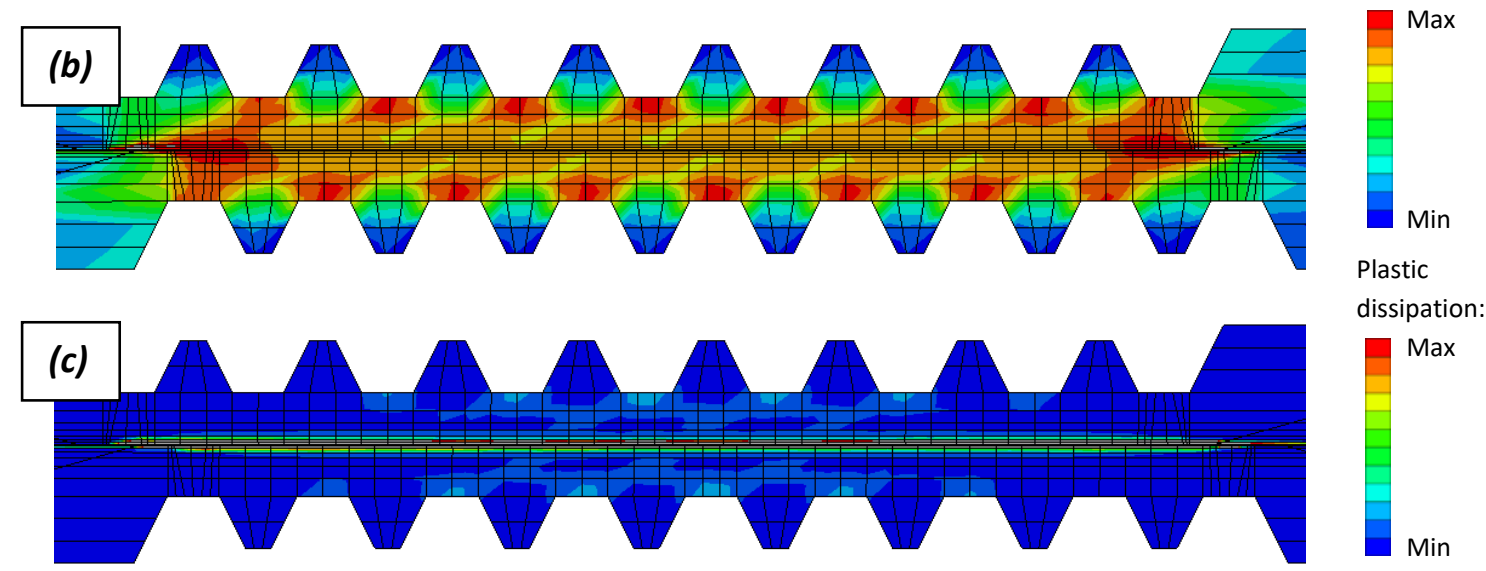

Figure 14 Tool misalignment and shear bands observed in an $\mathrm{Al}-\mathrm{Al}$ weld at $0.5 \mathrm{~s}$.

(a) Experimental image of a cross-section; (b) map of von Mises stress;

(c) map of plastic dissipation.

\section{Conclusions}

Heat generation in ultrasonic welding was successfully predicted using 3D thermal and deformation models, for three material combinations: Al 6111 to itself, and to DC04 steel and Ti6Al4V. The model demonstrated a number of innovative features:

(1) computational efficiency was obtained by running the more complex deformation model for single cycles at intervals during the continuous thermal analysis, and was limited to the fully bonded second stage of USW (which is of most interest for modelling joint degradation due to intermetallic formation in dissimilar alloy welds).

(2) the predicted heat generation was validated independently against the power history inferred from thermocouple measurements, with the best agreement being obtained when the material strength included an empirical reduction of $25 \%$, which is consistent with ultrasonic softening behaviour reported in the literature.

(3) material deformation maps were presented as a means of identifying the dominant deformation regime of temperature and strain-rate during welding. 
(4) as a proof of concept, the thermal and deformation models were fully coupled, with the predicted heat generation from the deformation model becoming the heat input for the next increment of the thermal model. Hence the power and temperature histories could be successfully predicted from first principles, directly from the constitutive data and a kinematic description of the process.

(5) tool misalignment was shown to be a potential source of shear banding in the weld, but was found to have a negligible influence on the net heat generation.

\section{Acknowledgements}

The work described in this paper was initially funded by the UK Engineering and Physical Sciences Research Council (EPSRC) via the grant Friction Joining - Low Energy Manufacturing for Hybrid Structures in Fuel Efficient Transport Applications (EP/G022674/1), and subsequently by EPSRC through the University of Cambridge Doctoral Training Account, with additional CASE award funding provided by TWI, Granta Park, Cambridge, UK. The authors gratefully acknowledge the technical discussions of this work with Dr Graham McShane and Dr Aidan Reilly (CUED), Prof. Phil Prangnell and Prof. Joseph Robson (Manchester University). We also thank Dimitrios Bakavos, Alexandra Panteli, Farid Haddadi, Chaoqun Zhang, Ying-Chun Chen and David Strong (Manchester University) for their assistance with the experiments. 
Appendix I: Thermal material properties
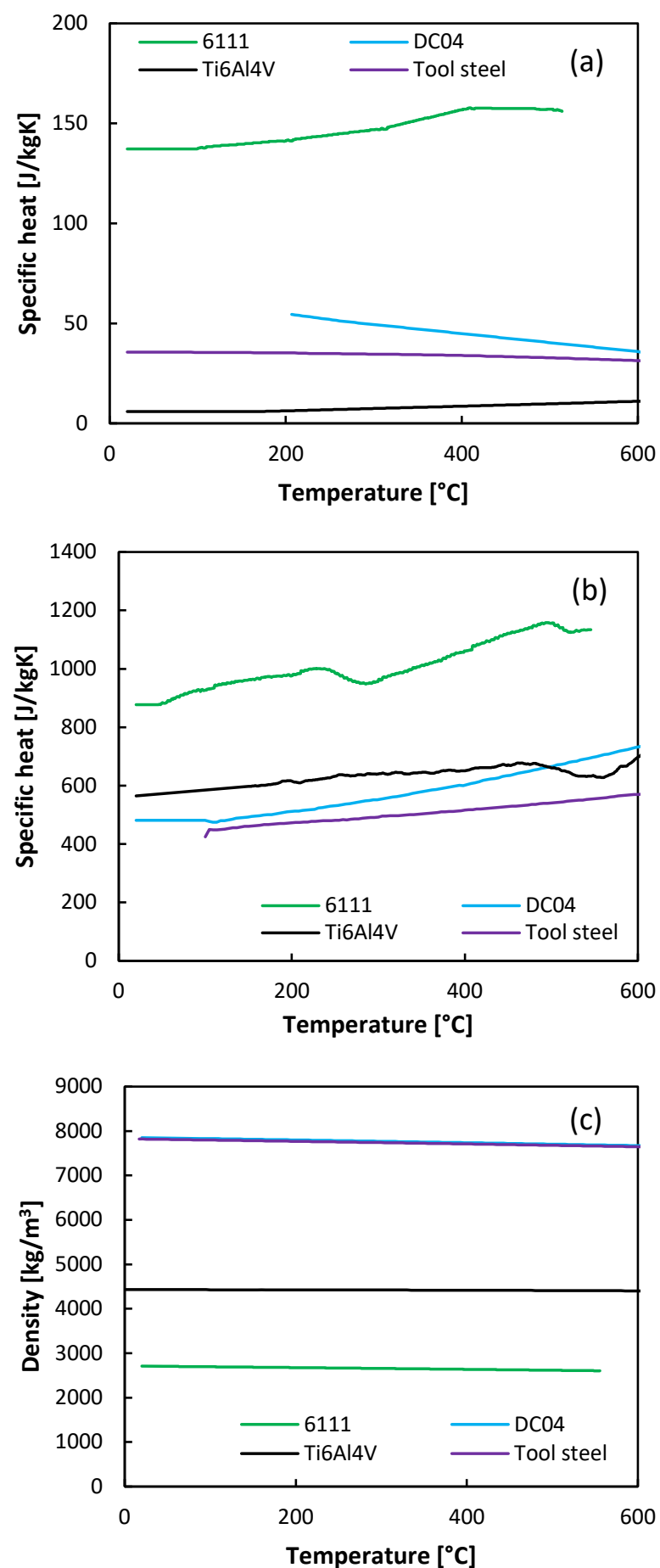

Figures AI.1 Thermal properties of Al alloy 6111, Ti alloy Ti6Al4V, steel DC04, and a tool steel [50-53] 


\section{Appendix II: Elastic material properties}
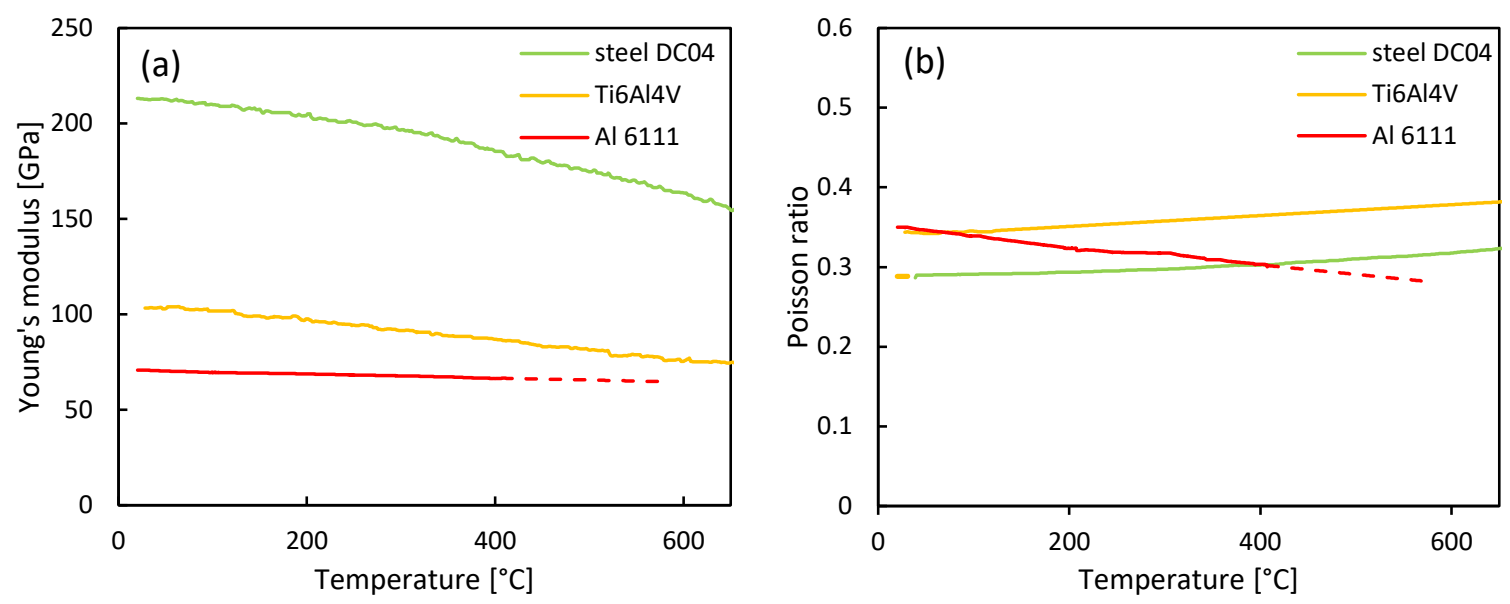

Figure AII.1 (a) Young’s modulus, (b) Poisson's ratio, for Al alloy 6111 [36], Ti alloy Ti6Al4V [37], and steel DC04 [37]

(solid line - data from the source; dashed line - linear extrapolation up to $\mathrm{T}_{\text {solidus }}$ )

\section{Appendix III: Constitutive equations}

The following appendix presents equations for the best fit curves to the collated experimental flow stress data for aluminium 6111. A polynomial relationship between yield stress and temperature was obtained via the method of least squares. The yield stress at other strain-rates was then found by assuming a linear scaling relationship between stress and $\log ($ strain-rate). The polynomial fit describes the flow stress between room temperature and the maximum temperature for which experimental data was available, $\mathrm{T}_{\text {exp-max }}$, beyond which a linear decrease in flow stress to zero at solidus temperature was assumed in all cases. Identical units are used: $\sigma$ is expressed in [MPa], $\mathrm{T}$ is expressed in $\left[{ }^{\circ} \mathrm{C}\right]$ and $\dot{\varepsilon}$ is expressed in $\left[s^{-1}\right]$. The model describes the behaviour at the nominal plastic strain of $10 \%$, and does not include the influence of ultrasonic softening.

$\left\{\begin{array}{l}\sigma(\dot{\varepsilon}=0.1)=3.63 E-9 T^{4}-7.85 E-8 T^{3}-0.00207 T^{2}-0.193 T+222.32 \\ \sigma(\dot{\varepsilon})=\sigma(\dot{\varepsilon}=0.1)+\log \dot{\varepsilon}\left(-2.28 E-4 T^{2}+0.165 T-14\right)\end{array}\right.$

$\mathrm{T}_{\text {exp-max }}=550^{\circ} \mathrm{C}$

$\mathrm{T}_{\text {solidus }}=647^{\circ} \mathrm{C}$

Nominal plastic strain $=0.1$ 


\section{References}

[1] D. Bakavos, P.B. Prangnell, "Mechanisms of joint and microstructure formation in high power ultrasonic spot welding 6111 aluminium automotive sheet," Mater. Sci. Eng.: A, vol. 527, p. 6320-6334, 2010.

[2] P. Prangnell, F. Haddadi, Y. C. Chen, "Ultrasonic spot welding of aluminium to steel for automotive applications - microstructure and optimisation," Mater Sci. Technol., vol. 27, pp. 617-624, 2011.

[3] A. Panteli, J.D. Robson, I. Brough, P.B. Prangnell, "The effect of high strain rate deformation on intermetallic reaction during ultrasonic welding aluminium to magnesium," Mater. Sci. Eng.: A, vol. 556, pp. 31-42, 2012.

[4] C.Q.Zhang, J.D.Robson, O.Ciuca, P.B.Prangnell, "Microstructural characterization and mechanical properties of high power ultrasonic spot welded aluminum alloy AA6111-TiAl6V4 dissimilar joints," Mater. Charact., vol. 97, pp. 83-91, 2014.

[5] Y.C. Chen, D. Bakavos, A. Gholinia, P.B. Prangnell, "HAZ development and accelerated postweld natural ageing in ultrasonic spot welding aluminium 6111-T4 automotive sheet," Acta Mater., vol. 60, no. 6-7, pp. 2816-2828, 2012.

[6] C.Q.Zhanga, J.D.Robson, P.B.Prangnell, "Dissimilar ultrasonic spot welding of aerospace aluminum alloy AA2139 to titanium alloy TiAl6V4," J. Mater. Process. Technol., vol. 231, pp. 382-388, 2016.

[7] J. Robson, A. Panteli, P.B. Prangnell, "Modelling intermetallic phase formation in dissimilar metal ultrasonic welding of aluminium and magnesium alloys," Sci. Technol. Weld. Joining, vol. 17, no. 6, pp. 447-453, 2012.

[8] P. Jedrasiak, H.R. Shercliff, Y.C. Chen, L. Wang, P. Prangnell, "Modeling of the Thermal Field in Dissimilar Alloy Ultrasonic Welding," J. Mater. Eng. Perform., vol. 24, no. 2, pp. 799-807, 2015.

[9] L. Wang, Y. Wang, P. Jedrasiak, H.R. Shercliff, P.B. Prangnell, J.D. Robson, "Modelling of intermetallic compound growth kinetics during solid state welding," unpublished work.

[10] S. Elangovan, S. Semeer, K. Prakasan, "Temperature and stress distribution in ultrasonic metal welding-An FEA-based study," Journal of Materials Processing Technology, vol. 209, pp. 1143-2250, 2009.

[11] E. Sooriyamoorthy, S. Ponnayya, J. Henry, P. Kalakkath, "Experimental studies on optimization of process parameters and finite element analysis of temperature and stress distribution on joining of $\mathrm{Al}-\mathrm{Al}$ and $\mathrm{Al}-\mathrm{Al} 2 \mathrm{O} 3$ using ultrasonic welding," The International Journal of Advanced Manufacturing Technology, vol. 55, pp. 631-640, 2011.

[12] A. Siddiq, E. Ghassemieh, "Thermomechanical analyses of ultrasonic welding process using thermal and acoustic softening effects," Mechanics of Materials, vol. 40, p. 982-1000, 2008.

[13] A. Siddiq, E. Ghassemieh, "Theoretical and FE Analysis of Ultrasonic Welding of Aluminum Alloy 3003," Journal of Manufacturing Science and Engineering, vol. 131, pp. 041007.1041007.11, 2009.

[14] W. Kim, A. Argento, A. Grima, D. Scholl, S. Ward, "Thermo-mechanical analysis of frictional heating in ultrasonic spot welding of aluminium plates," Proceedings of the Institution of Mechanical Engineers, Part B: Journal of Engineering Manufacture, vol. 225, no. B7, pp. 1093- 
1103, 2011.

[15] C. Doumanidis, Y. Gao, "Mechanical modeling of ultrasonic welding," Welding Journal, vol. 83, no. 4, pp. 140S-146S, 2004.

[16] Y. Gao, C. Doumanidis, "Mechanical Analysis of Ultrasonic Bonding for Rapid Prototyping," Journal of Manufacturing Science and Engineering, vol. 124, no. 2, pp. 426-434, 2002.

[17] C. Zhang, L. Li, "Effect of substrate dimensions on dynamics of ultrasonic consolidation," Ultrasonics, vol. 50, p. 811-823, 2010.

[18] C. Zhang, L.J. Li, "A Coupled Thermal-Mechanical Analysis of Ultrasonic Bonding Mechanism," Metallurgical and Materials Transactions B: Process metallurgy and materials processing science, vol. 40, no. 2, pp. 196-207, 2009.

[19] C. Zhang, L. Li, "A Friction-Based Finite Element Analysis of Ultrasonic Consolidation," Welding Journal, vol. 87, pp. 187-194, 2008.

[20] D. Lee, E. Kannatey-Asibu, W. Cai, "Ultrasonic Welding Simulations for Multiple Layers of Lithium-Ion Battery Tabs," Journal of Manufacturing Science and Engineering, vol. 135, no. 6, pp. 061011-1-13, 2013.

[21] D. Lee, W. Cai, "The effect of horn knurl geometry on battery tab ultrasonic welding quality: 2D finite element simulations," Journal of Manufacturing Processes, vol. 28, no. 3, pp. 428-441, 2017.

[22] K. Chen, Y. Zhang , "Mechanical analysis of ultrasonic welding considering knurl pattern of sonotrode tip," Materials \& Design, vol. 87, pp. 393-404, 2015.

[23] K.K. Chen, Y. S. Zhang, "Numerical analysis of temperature distribution during ultrasonic welding process for dissimilar automotive alloys," Science and Technology of Welding and Joining, vol. 20, no. 6, pp. 522-531, 2015.

[24] K.K. Chen, Y.S. Zhang , H.Z. Wang, "Study of plastic deformation and interface friction process for ultrasonic welding," Science and Technology of Welding and Joining, vol. 22, no. 3, pp. 208216, 2017.

[25] K. Chen, Y. Zhang Y, H. Wang, "Effect of acoustic softening on the thermal-mechanical process of ultrasonic welding," Ultrasonics, vol. 75, pp. 9-21, 2017.

[26] N. Shen, A. Samanta, H. Ding, W.W.Cai, "Simulating Microstructure Evolution of Ultrasonic Welding of Battery Tabs," Journal of Manufacturing Processes, vol. 23, pp. 306-314, 2016.

[27] T.T. Ngo, J.H. Huang, C.C. Wang, "The BFGS method for estimating the interface temperature and convection coefficient in ultrasonic welding," International Communications in Heat and Mass Transfer, vol. 69, pp. 66-75, 2015.

[28] J.H. Huang, T.T. Ngo, C.C. Wang, "HSDM and BFGS method for determining the heat generation and range of heat distribution in 2-D ultrasonic seam welding problems," Numerical Heat Transfer, Part B: Fundamentals, vol. 69, no. 1, pp. 48-67, 2016.

[29] P. Jedrasiak and H.R. Shercliff, "Modelling of heat generation in friction stir spot welding using a small strain finite element method," (unpublished work).

[30] A. Panteli, "Friction Joining of Aluminium-to-Magnesium for Lightweight Automotive Applications (PhD thesis)," Manchester University School of Materials, Manchester, UK, 2012.

[31] F. Haddadi, "Joint Performance and Interface Reactions in Dissimilar Aluminium to Steel Ultrasonic Spot Welding (PhD thesis)," Manchester University School of Materials, Manchester, UK, 2012.

[32] A. Panteli, Y.C. Chen, D. Strong, X.Y. Zhang, P.B. Prangnell, "Optimization of Aluminium-to- 
Magnesium Ultrasonic Spot Welding," JOM, vol. 64, no. 3, pp. 414-420, 2012.

[33] F. Haddadi, D. Strong, P. B. Prangnell, "Effect of Zinc Coatings on Joint Properties and Interfacial Reactions in Aluminum to Steel Ultrasonic Spot Welding," JOM, vol. 64, no. 3, pp. 407-413, 2012.

[34] P. Jedrasiak, "Thermomechanical modelling of friction welding (PhD thesis)," Cambridge University Engineering Department, Cambridge, UK, 2017.

[35] H. Watanabe, T. Mukai, M. Sugioka, K. Ishikawa, "Elastic and damping properties from room temperature to 673 K in an AZ31 magnesium alloy," Scr. Mater., vol. 51, pp. 291-295, 2004.

[36] S.K. Khanna, X. Long, W.D. Porter, H. Wang, C.K. Liu, M. Radovic, E. Lara-Curzio, "Residual stresses in spot welded new generation aluminium alloys Part A - thermophysical and thermomechanical properties of 6111 and 5754 aluminium alloys," Sci. Technol. Weld. Joining, vol. 10, pp. 82-87, 2005.

[37] M. Fukuhara, A. Sanpei, "Elastic moduli and internal frictions of Inconel 718 and Ti-6AI-4V as a function of temperature," J. Mater. Sci. Lett., vol. 12, no. 14, pp. 1122-1124, 1993.

[38] J. Ding, G. Kang, Q. Kan, Y. Liu, "Constitutive model for uniaxial time-dependent ratcheting of 6061-T6 aluminum alloy," Comp. Mater. Sci. , vol. 57, p. 67-72, 2012.

[39] L.D. Oosterkamp, A. Ivankovic, G. Venizelos, "High strain rate properties of selected aluminium alloys," Materials Science and Engineering A, vol. 278, p. 225-235, 2000.

[40] F. Yafu, W. Qu-dong, N. Jun-sheng, C. Jie, J. Wei, "Experimental Measure of Parameters: The Johnson-Cook Material Model of Extruded Mg-Gd-Y Series Alloy," Journal of Applied Mechanics, vol. 77, pp. 051902-1-5, 2010.

[41] F. Feng, S. Huang, Z. Meng, J. Hu, Y. Lei, M. Zhou, Z. Yang, "A constitutive and fracture model for AZ31B magnesium alloy in the tensile state," Materials Science and Engineering: A, vol. 594, p. 334-343, 2014.

[42] P.A. Colegrove, H.R. Shercliff, R. Zettler, "Model for predicting heat generation and temperature in friction stir welding from the material properties," Sci. Technol. Weld. Joining, vol. 12, no. 4, pp. 284-297, 2007.

[43] L. Hua, F. Meng, Y. Song, J. Liu, X. Qin, L. Suo, "J. Mater. Eng. Perform.," A Constitutive Model of 6111-T4 Aluminum Alloy Sheet Based on the Warm Tensile Test, vol. 23, no. 3, pp. 1107-1113, 2014.

[44] L. Fu, B. Wang, J. Zhou, J. Lin, "Constitutive equation for hot deformation behavior of 6111 aluminum alloy," J. Plasticity Eng., vol. 20, pp. 107-111, 2013.

[45] A.A. Sa'ardin, "Characterising the effective material softening in ultrasonic forming of metals (PhD thesis)," University of Glasgow, Glasgow, UK, 2012.

[46] Y. Daud, M. Lucas, Z. Huang, "Modelling the effects of superimposed ultrasonic vibrations on tension and compression tests of aluminium," J. Mater. Process. Tech., vol. 186, no. 1-3, p. 179190, 2007.

[47] Z. Yao, G.Y. Kim, L. Faidley, Q. Zou, D. Mei, Z. Chen, "Effects of superimposed highfrequency vibration on deformation of aluminum in micro/meso-scale upsetting," J. Mater. Process. Tech., vol. 212, no. 3, p. 640-646, 2012.

[48] J.C. Hung, C. Hung, "The influence of ultrasonic-vibration on hot upsetting of aluminum alloy," Ultrasonics, vol. 43, no. 8, p. 692-698, 2005.

[49] P.A. Colegrove, H.R. Shercliff, "CFD modelling of friction stir welding of thick plate 7449 aluminium alloy," Sci. Technol. Weld. Joining, vol. 11, no. 4, pp. 429-441, 2006. 
[50] S.K. Khanna, X. Long, W.D. Porter, H. Wang, C.K. Liu, M. Radovic, E. Lara-Curzio, "Residual Stresses in Spot Welded New Generation Aluminium Alloys Part A-Thermophysical and Thermomechanical Properties of 6111 and 5754 Aluminium Alloys," Science and Technology of Welding and Joining, vol. 10, no. 1, p. 82-87,2005

[51] S. Lee, H.J. Ham, S.Y. Kwon, S.W. Kim, C.M. Suh, "Thermal Conductivity of Magnesium Alloys in the Temperature Range from $-125^{\circ} \mathrm{C}$ to $400{ }^{\circ} \mathrm{C}$," International Journal of Thermophysics, vol. 34, no. 12, pp. 2343-2350, 2013.

[52] M.E. Alam, S. Han, Q.B. Nguyen, A.M.S. Hamouda, M. Gupta, "Development of new magnesium based alloys and their nanocomposites," Journal of Alloys and Compounds, vol. 509, no. 34, p. 8522-8529, 2011.

[53] G. Elert, "The Physics Factbook: Density of Steel," [Online]. Available: http://hypertextbook.com/facts/2004/KarenSutherland.shtml. [Accessed 07 January 2014]. 